University of Nebraska - Lincoln

DigitalCommons@University of Nebraska - Lincoln

Publications, Agencies and Staff of the U.S.

Department of Commerce

U.S. Department of Commerce

2011

\title{
Satellite cloud and precipitation assimilation at operational NWP centres
}

Peter Bauer

European Centre for Medium-Range Weather Forecasts, peter.bauer@ecmwf.int

Thomas Auligné

National Center for Atmospheric Research

William Bell

European Centre for Medium-Range Weather Forecasts

Alan Geer

European Centre for Medium-Range Weather Forecasts

Vincent Guidard

Météo-France

See next page for additional authors

Follow this and additional works at: https://digitalcommons.unl.edu/usdeptcommercepub

Part of the Environmental Sciences Commons

Bauer, Peter; Auligné, Thomas; Bell, William; Geer, Alan; Guidard, Vincent; Heilliette, Sylvain; Kazumori, Masahiro; Kim, Min-Jeong; Liu, Emily H.-C.; McNally, Anthony P.; Macpherson, Bruce; Okamoto, Kozo; Renshaw, Richard; and Riishøjgaard, Lars-Peter, "Satellite cloud and precipitation assimilation at operational NWP centres" (2011). Publications, Agencies and Staff of the U.S. Department of Commerce. 240.

https://digitalcommons.unl.edu/usdeptcommercepub/240

This Article is brought to you for free and open access by the U.S. Department of Commerce at DigitalCommons@University of Nebraska - Lincoln. It has been accepted for inclusion in Publications, Agencies and Staff of the U.S. Department of Commerce by an authorized administrator of DigitalCommons@University of Nebraska - Lincoln. 


\section{Authors}

Peter Bauer, Thomas Auligné, William Bell, Alan Geer, Vincent Guidard, Sylvain Heilliette, Masahiro

Kazumori, Min-Jeong Kim, Emily H.-C. Liu, Anthony P. McNally, Bruce Macpherson, Kozo Okamoto, Richard

Renshaw, and Lars-Peter Riishøjgaard 


\title{
RMetS
}

\section{Satellite cloud and precipitation assimilation at operational NWP centres}

\author{
Peter Bauer, ${ }^{a \star}$ Thomas Auligné,${ }^{\mathrm{b} \dagger}$ William Bell, ${ }^{\mathrm{a}}$ Alan Geer, ${ }^{\mathrm{a}}$ Vincent Guidard, ${ }^{\mathrm{c}}$ Sylvain \\ Heilliette, ${ }^{\mathrm{d} \ddagger}$ Masahiro Kazumori, ${ }^{\mathrm{e}}$ Min-Jeong Kim, ${ }^{\mathrm{f}}$ Emily H.-C. Liu, ${ }^{\mathrm{g} \dagger}$ Anthony P. McNally, ${ }^{\mathrm{a}}$ \\ Bruce Macpherson, ${ }^{\mathrm{h} \S}$ Kozo Okamoto, ${ }^{\mathrm{e}}$ Richard Renshaw ${ }^{\mathrm{h} \S}$ and Lars-Peter Riishøjgaard ${ }^{\mathrm{i} \dagger}$ \\ ${ }^{a}$ European Centre for Medium-Range Weather Forecasts, Reading, UK \\ ${ }^{\mathrm{b}}$ National Center for Atmospheric Research, Boulder, Colorado, USA \\ ${ }^{c}$ Météo-France, Toulouse, France \\ ${ }^{\mathrm{d}}$ Environment Canada, Dorval, Québec, Canada \\ 'Japan Meteorological Agency, Tokyo, Japan \\ ${ }^{\mathrm{f}}$ Cooperative Institute for Research in the Atmosphere, Colorado State University, Fort Collins, USA \\ ${ }^{\mathrm{g}} \mathrm{NOAA} / \mathrm{NCEP} / \mathrm{EMC}$, Camp Springs, Maryland and Systems Research Group, Colorado Springs, USA \\ ${ }^{\mathrm{h}}$ Met Office, Exeter, UK \\ iJCSDA, GMAO, NASA Goddard Space Flight Center, Greenbelt, Maryland, USA \\ ${ }^{*}$ Correspondence to: P. Bauer, ECMWF, Shinfield Park, Reading RG2 9AX, UK. E-mail: peter.bauer@ecmwf.int \\ ${ }^{\dagger}$ The contribution of these authors to this article was prepared as part of their official duties as United States Federal \\ Government employees. \\ \#The contribution of this author was prepared as part of his official duties as a Canadian government employee. \\ ${ }^{\S}$ The contribution of these authors was written in the course of their employment at the Met Office, UK, and is published \\ with the permission of the Controller of HMSO and the Queen's Printer for Scotland.
}

The status of current efforts to assimilate cloud- and precipitation-affected satellite data is summarised with special focus on infrared and microwave radiance data obtained from operational Earth observation satellites. All global centres pursue efforts to enhance infrared radiance data usage due to the limited availability of temperature observations in cloudy regions where forecast skill is estimated to strongly depend on the initial conditions. Most systems focus on the sharpening of weighting functions at cloud top providing high vertical resolution temperature increments to the analysis, mainly in areas of persistent high and low cloud cover. Microwave radiance assimilation produces impact on the deeper atmospheric moisture structures as well as cloud microphysics and, through control variable and background-error formulation, also on temperature but to lesser extent than infrared data. Examples of how the impacts of these two observation types are combined are shown for subtropical low-level cloud regimes. The overall impact of assimilating such data on forecast skill is measurably positive despite the fact that the employed assimilation systems have been constructed and optimized for clear-sky data. This leads to the conclusion that a better understanding and modelling of model processes in cloud-affected areas and data assimilation system enhancements through inclusion of moist processes and their error characterization will contribute substantially to future forecast improvement. Copyright (C) 2011 Royal Meteorological Society, Crown in the right of Canada, and British Crown copyright, the Met Office

Key Words: data assimilation; satellite observations

Received 7 February 2011; Revised 6 July 2011; Accepted 14 July 2011; Published online in Wiley Online Library

Citation: Bauer P, Auligné T, Bell W, Geer A, Guidard V, Heilliette S, Kazumori M, Kim M-J, Liu EH-C, McNally AP, Macpherson B, Okamoto K, Renshaw R, Riishøjgaard L-P. 2011. Satellite cloud and precipitation assimilation at operational NWP centres. Q. J. R. Meteorol. Soc. DOI:10.1002/qj.905 


\section{Introduction}

With modern data assimilation techniques, the vast amount of conventional and satellite-observed information is efficiently used to produce accurate initial conditions for the forecast model that are spatially, temporally and physically consistent and thus produce a seamless information transfer from the analysis into the forecast. Regarding satellite observations, the areas affected by clouds and precipitation are less well represented because it is difficult to separate the information on the main observables, such as temperature and moisture, from cloud and precipitation effects. Satellite observations that are sensitive to clouds are often sensitive to surfaces as well, so that surface contributions to the signal further reduce the atmospheric signal-to-(geophysical)noise ratio. Cloud-affected observations thus introduce the combined sensitivity to clear, cloud and surface variables and require that these are accurately represented by the model.

Previous studies have indicated that cloud-affected areas coincide with areas where uncertainties in the initial conditions can produce large forecast error growth (McNally, 2002). This has been mostly related to constraining temperature rather than moisture since moisture analysis increments dissipate quickly with forecast range. Adding such observations thus promises better analyses and better forecasts, at least for a forecast range similar to the lifetime of the adjusted processes.

Since cloudy areas in models currently have little direct constraint from satellite observations, the analysis is driven by the model background and by observations located away from cloudy areas (unless conventional observations are available that are assimilated as cloud-free). Despite this, global numerical weather prediction (NWP) produces rather accurate cloud and precipitation forecasts, at least in regimes where small-scale features such as convection and high temporal variability are less important. For example, global NWP precipitation forecasts in midlatitude winter conditions outperform most satellite-derived rainfall products (Ebert et al., 2007). However, this accuracy mostly relates to mean statistics and rainfall aggregated over at least 6-12 h periods (Lopez, 2011), while the intercomparison of instantaneous observations with model predictions at grid-box and model time-step scales can exhibit substantial differences, largely due to misplacement errors.

When cloud-affected data assimilation is envisaged, an important distinction is whether it is intended to improve the analysis of temperature and moisture in the presence of clouds, e.g. the free atmosphere above cloud top, or to improve the analysis of clouds and precipitation and, consequently, also temperature and moisture inside clouds. This affects the choice of observation type and also depends on how the relationship between temperature/moisture and cloud variables is formulated, in both model and background-error covariance statistics.

Intuitively, one could argue that adjusting the entire state vector at once with more physical complexity would always produce a more consistent analysis solution. However, Pincus et al. (2011) show in an idealized data assimilation framework that more complex models with more degrees of freedom can actually dilute the impact of cloud observations on the dry variables, as well as the interaction between physics and dynamics, and thus reduce the overall forecast impact. The choice of control variable and the formulation of model background-error covariances thus represent other important elements in this multivariate optimization problem (Ménétrier and Montmerle, 2011; Michel et al., 2011).

Microwave radiance observations penetrate clouds but contain little information on vertical condensate, temperature and moisture distributions, but instead constrain the state in the entire cloud column. If temperature and moisture above clouds are targeted, the nearly complete absorption of infrared radiation at cloud top can be used to provide a well-defined lower-boundary condition in the radiative transfer calculations. This only affects the clear-sky column above the cloud and will have little impact on the cloud itself.

The assimilation of cloud-affected observations raises a number of issues that can be in conflict with fundamental assumptions being made in current operational data assimilation systems. These assumptions are that

(i) the short-range forecast constraining the analysis is already close to the true state so that the minimization can be performed assuming linearity of forecast model and observation operator over the assimilation window (usually $6-12 \mathrm{~h}$ );

(ii) the currently employed covariance structures are often isotropic and homogeneous;

(iii) the model biases are of small magnitude, and

(iv) model error growth is absent in the assimilation window.

The above-mentioned displacement error already causes serious problems under these assumptions (Geer and Bauer, 2010).

These fundamental issues have been discussed in detail by Errico et al. (2007, 2008) and Vukicevic (2008), and require different solutions for microwave, infrared satellite radiometer, and ground-based observations, or as a function of data assimilation system or the targeted spatial-temporal scales. This is why we focus here on global and operational systems and mostly satellite-based observations to avoid case-study-dependent interpretation and to remain with fundamental rather than specialized issues. We also restrict ourselves to radiance observations since they can be treated more consistently in current data assimilation systems than retrieval products (Andersson et al., 2004).

This article gives an update on status and activities towards the improvement of the use of cloud-affected radiance observations at global NWP centres. Section 2 gives a brief overview of the available systems, which is required to interpret the studies presented in section 3 related to infrared (section 3.2) and microwave (section 3.3) radiance observations, focussing on regions of low cloud over subtropical oceans to investigate the consistency between the impact of the two observation types. The article finishes with conclusions and an outlook towards future developments for operational application in section 4 .

\section{NWP systems}

Table I gives a brief overview of the main model and data assimilation components that are relevant for cloud and precipitation assimilation at those NWP centres covered here. Only the main model features relevant to the subject of this article have been included and the physical process parametrizations have been limited to those of clouds and convection. For more details, refer to the cited literature. 
Table I. Short summary of global NWP centre model features relevant to clouds and precipitation assimilation.

\begin{tabular}{|c|c|c|c|}
\hline $\begin{array}{l}\text { NWP centre } \\
\text { (models) }\end{array}$ & $\begin{array}{l}\text { ECMWF } \\
\text { (IFS) }\end{array}$ & $\begin{array}{l}\text { Environment Canada } \\
\text { (GEM) }\end{array}$ & $\begin{array}{l}\text { Japan Meteorological Agency } \\
\text { (GSM, MSM) }\end{array}$ \\
\hline \multicolumn{4}{|l|}{ Model } \\
\hline Global & $\begin{array}{l}\text { Spectral T1279 }(16 \mathrm{~km}) \text {, } \\
91 \text { levels (top } 0.01 \mathrm{hPa}), \\
10 \text { min time step } \\
\text { (semi-Lagrangian). }\end{array}$ & $\begin{array}{l}\text { Uniform } 600 \times 300\left(33 \mathrm{~km} \text { at } 49^{\circ} \text { lat.), }\right. \\
\text { hybrid } 80 \text { levels (top } 0.1 \mathrm{hPa}), \\
10 \text { min time step } \\
\text { (semi-Lagrangian). }\end{array}$ & $\begin{array}{l}\text { Spectral T959 }(20 \mathrm{~km}) \text {, } \\
60 \text { levels (top } 0.1 \mathrm{hPa}), \\
10 \text { min time step } \\
\text { (semi-Lagrangian). }\end{array}$ \\
\hline Regional & N/A & $\begin{array}{l}\text { Regional model not used with } \\
\text { cloud/rain-affected observations. }\end{array}$ & $\begin{array}{l}\text { Non-hydrostatic gridpoint, } \\
\text { top near } 22 \mathrm{~km} \text {, } \\
5 \mathrm{~km}(15 \mathrm{~km}) \text { horiz. resolution } \\
\text { in outer (inner) loop. }\end{array}$ \\
\hline
\end{tabular}

Physics

Cloud

Convection

Tiedke (1989);

Bechtold et al. (2008)

Linearized

Tompkins and

Janisková (2004)

cloud

Tiedke (1993);

Tompkins (2008)

Sundqvist (1978); Geleyn (1987);

Pudykiewicz et al. (1992)

Kain and Fritsch (1990, 1993);

Belair et al. (2005)

Zadra et al. (2004)

Mahfouf (2005)

\begin{abstract}
Linearized Lopez and
\end{abstract}
convection Moreau (2005)

Data assimilation

System

Global: Incremental 4D-Var

(Rabier et al., 2000)

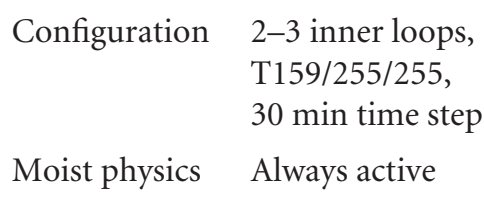

Global: Sommeria and

Deardorff (1977),

Sundqvist (1978), Smith (1990).

Regional: 6 categories bulk microphysics (JMA, 2007).

Global: Arakawa

and Schubert (1974).

Regional: Modified Kain-

Fritsch scheme (JMA, 2007).

Global: JMA (2007).

Regional: Simplified moist physics of large-scale condensation

(Honda et al., 2005).

Global: JMA (2007).

Regional: none.
Global: Incremental 4D-Var

(Gauthier et al., 2007,

Laroche et al., 2007).

Regional: 3D-Var

(Fillion et al., 2010).

2 inner loops, regular $240 \times 120$

(T108, $170 \mathrm{~km}$ at $49^{\circ}$ lat.),

30 min time step

Diabatic 1st inner loop

Global: Incremental 4D-Var (JMA, 2007).

Regional: Incremental 4D-Var (Honda et al., 2005).

Global: 1 inner loop, T159L60. Regional: 1 inner loop, $15 \mathrm{~km}$, 40 layers, variable time step.

Global: Simple physics and advanced physics (35 iterations). Regional: Moist physics always active and trajectory updated every iteration by nonlinear forward model.

Log. of spec. humidity

Global: Log. of spec. humidity. Regional: Pseudo RH.

\begin{tabular}{|c|c|c|c|}
\hline $\begin{array}{l}\text { Moist control } \\
\text { variable }\end{array}$ & $\begin{array}{l}\text { Normalized RH } \\
\text { (Andersson et al., 2007). }\end{array}$ & Log. of spec. humidity & $\begin{array}{l}\text { Global: Log. of spec. humidity. } \\
\text { Regional: Pseudo RH. }\end{array}$ \\
\hline \multicolumn{4}{|c|}{ Cloud/precipitation data } \\
\hline $\begin{array}{l}\text { Global: } \\
\text { Infrared }\end{array}$ & $\begin{array}{l}\text { HIRS/AIRS/IASI } \\
\text { overcast radiances in } \\
\text { 4D-Var (McNally, 2009). }\end{array}$ & N/A & N/A \\
\hline $\begin{array}{l}\text { Global: } \\
\text { Microwave }\end{array}$ & $\begin{array}{l}\mathrm{SSMI}(\mathrm{S}) / \mathrm{AMSR}-\mathrm{E} / \mathrm{TMI} \\
\text { radiances in } 4 \mathrm{D}-\mathrm{Var} \\
\text { (Bauer } \text { et al., 2010; } \\
\text { Geer } \text { et al., 2010). }\end{array}$ & N/A & $\begin{array}{l}\text { AMSR-E/TMI retrieved } \\
\text { precipitation in } 4 \mathrm{D}-\mathrm{Var} \\
\text { (Tauchi et al., 2004) in MSM. }\end{array}$ \\
\hline Regional & N/A & N/A & $\begin{array}{l}\text { Ground-based radar precipitation } \\
\text { (Koizumi et al., 2005). }\end{array}$ \\
\hline
\end{tabular}


Table I (Continued)

\begin{tabular}{|c|c|c|c|}
\hline $\begin{array}{l}\text { NWP centre } \\
\text { (models) }\end{array}$ & $\begin{array}{l}\text { Météo-France } \\
\text { (ARPEGE, AROME) }\end{array}$ & $\begin{array}{l}\text { Met Office } \\
\text { (UM, NAE, UK) }\end{array}$ & $\begin{array}{l}\text { NCEP } \\
\text { (GFS, NAM, WRF) }\end{array}$ \\
\hline \multicolumn{4}{|l|}{ Model } \\
\hline Global & $\begin{array}{l}\text { Spectral T798 } \\
(10-60 \mathrm{~km} \text {, stretched), } \\
70 \text { levels (top } 0.1 \mathrm{hPa}), \\
10 \text { min time step. }\end{array}$ & $\begin{array}{l}\text { Grid-point N512 }(25 \mathrm{~km}) \text {, } \\
70 \text { levels (top } 80 \mathrm{~km}), \\
10 \text { min time step. }\end{array}$ & $\begin{array}{l}\text { Eulerian T574L64 }(32 \mathrm{~km}) \\
\text { for range } 0-192 \mathrm{~h} \text { and } \\
\text { T190L64 }(110 \mathrm{~km}) \\
\text { for range } 192-384 \mathrm{~h}, \\
64 \text { levels (top } 0.2 \mathrm{hPa})\end{array}$ \\
\hline Regional & $\begin{array}{l}\text { Non-hydrostatic }(2.5 \mathrm{~km}) \text {, } \\
60 \text { levels (top } 1 \mathrm{hPa}) \\
1 \text { min time step. }\end{array}$ & $\begin{array}{l}\text { NAE: grid-point } 12 / 36 \mathrm{~km} \text {, } \\
70 \text { levels (top } 80 \mathrm{~km} \text { ), } \\
5 \text { min time step. } \\
\text { UK: grid-point variable } \\
1.5 \mathrm{~km} \text { grid, } 70 \text { levels } \\
\text { (top } 40 \mathrm{~km} \text { ), } 50 \text { s time step. }\end{array}$ & $\begin{array}{l}\text { Continental USA: } \\
\text { grid-point } 12 \mathrm{~km} \text {, } \\
60 \text { layers (top } 2 \mathrm{hPa} \text { ). }\end{array}$ \\
\hline \multicolumn{4}{|l|}{ Physics } \\
\hline Cloud & $\begin{array}{l}\text { Lopez (2002), } \\
\text { Bouteloup et al. (2005). }\end{array}$ & $\begin{array}{l}\text { Global: Wilson et al. (2008). } \\
\text { Regional: Smith (1990). }\end{array}$ & $\begin{array}{l}\text { Sundqvist et al. (1989), } \\
\text { Zhao and Carr (1997). }\end{array}$ \\
\hline Convection & $\begin{array}{l}\text { Bougeault (1985), } \\
\text { Bechtold et al. (2001). }\end{array}$ & $\begin{array}{l}\text { Gregory and Rowntree (1990), } \\
\text { Gregory and Allen (1991), } \\
\text { Gregory et al. (1997). }\end{array}$ & $\begin{array}{l}\text { Simplified Arakawa-Schubert } \\
\text { (Grell, 1993; Pan and Wu, 1994; } \\
\text { Han and Pan, 2011) }\end{array}$ \\
\hline $\begin{array}{l}\text { Linearized } \\
\text { cloud }\end{array}$ & $\begin{array}{l}\text { Large-scale precipitation } \\
\text { (linearized Smith (1990) } \\
\text { cloud scheme + basic } \\
\text { autoconversion) }\end{array}$ & Stiller and Ballard (2009a) & $\begin{array}{l}\text { Grid-scale condensation scheme, } \\
\text { large-scale precipitation scheme }\end{array}$ \\
\hline $\begin{array}{l}\text { Linearized } \\
\text { convection }\end{array}$ & N/A & Stiller and Ballard (2009b) & Simplified Arakawa-Schubert \\
\hline \multicolumn{4}{|c|}{ Data assimilation } \\
\hline System & $\begin{array}{l}\text { Global: Incremental 4D-Var } \\
\text { (Rabier et al., 2000). } \\
\text { Regional: 3D-Var } \\
\text { (Brousseau et al., 2008). }\end{array}$ & $\begin{array}{l}\text { Global and NAE: } \\
\text { Incremental 4D-Var. } \\
\text { UK: 3D-Var } \\
\text { (Rawlins et al., 2007). }\end{array}$ & $\begin{array}{l}\text { Global and regional (GSI): } \\
\text { Incremental 3D-Var } \\
\text { (Derber and Wu, 1998; } \\
\text { Kleist et al., 1998). }\end{array}$ \\
\hline Configuration & $\begin{array}{l}2 \text { inner loops T107/323, } \\
30 / 22.5 \text { min. time step. }\end{array}$ & $\begin{array}{l}2 \text { inner loops; } \\
\text { global N108/N216, } \\
\text { NAE } 36 \text { km, UK } 3 \text { km. }\end{array}$ & $\begin{array}{l}2 \text { inner loops at the } \\
\text { resolution of T574/T574. }\end{array}$ \\
\hline Moist physics & Not active & Always active & Not active \\
\hline $\begin{array}{l}\text { Moist control } \\
\text { variable }\end{array}$ & Specific humidity & $\begin{array}{l}\text { 'Total' RH } \\
\text { (vapour plus cloud). }\end{array}$ & $\begin{array}{l}\text { Normalized } \mathrm{RH} \text { and } \\
\text { cloud water mixing ratio. }\end{array}$ \\
\hline \multicolumn{4}{|c|}{ Cloud/precipitation data } \\
\hline $\begin{array}{l}\text { Global: } \\
\text { Infrared }\end{array}$ & $\begin{array}{l}\text { AIRS: Pangaud et al. (2009). } \\
\text { IASI: Guidard } \\
\text { et al. (2011). }\end{array}$ & $\begin{array}{l}\text { AIRS/IASI cloudy radiances } \\
\text { through 1D-Var/4D-Var } \\
\text { (Pavelin et al., 2008). }\end{array}$ & N/A \\
\hline $\begin{array}{l}\text { Global: } \\
\text { Microwave }\end{array}$ & N/A & $\begin{array}{l}\text { AMSU-A channels } 1 \text { and } 2 \\
\text { in cloud, } 4 \mathrm{D} \text {-Var. }\end{array}$ & $\begin{array}{l}\text { TMI-retrieved surface } \\
\text { rainrate in global analysis. }\end{array}$ \\
\hline Regional & $\mathrm{N} / \mathrm{A}$ & $\begin{array}{l}\text { Radar rainrate (latent heat } \\
\text { nudging; Macpherson, 2001), } \\
\text { SEVIRI cloud fraction } \\
\text { (Taylor et al., 2008). } \\
\text { Analysed cloud fraction from } \\
\text { SEVIRI and surface reports } \\
\text { (Renshaw and Francis, 2011). }\end{array}$ & $\mathrm{N} / \mathrm{A}$ \\
\hline
\end{tabular}

Acronyms are explained in the text. 
The UK Met Office runs a global and various regional models. Each uses a different configuration of the same observation processing, assimilation and forecasting system. Data assimilation uses variational analysis (Rawlins et al. 2007). The forecast model is the Unified Model (UM; Davies et al., 2005), a non-hydrostatic grid-point model with a semiimplicit semi-Lagrangian integration scheme. The global and North Atlantic-Europe (NAE) models have a six-hourly data assimilation cycle using 4D-Var. The higher-resolution UK models ( $4 \mathrm{~km}$ regular grid and $1.5 \mathrm{~km}$ variable grid) use 3D-Var with a 3-hourly cycle. Forecasts are produced for a diverse range of customers and over a range of time-scales and resolutions. Each model produces forecasts four times a day, the global to $\mathrm{T}+144 \mathrm{~h}$, the NAE to $\mathrm{T}+60 \mathrm{~h}$, and the UK models to $\mathrm{T}+36 \mathrm{~h}$. The Met Office short-range ensemble system (MOGREPS) has a global $(60 \mathrm{~km}$ resolution, 70 levels) and a regional (NAE; $18 \mathrm{~km}$ resolution, 70 levels) component and both consist of 24 ensemble members. The global members provide the boundary conditions for the regional members and the ensembles are created from perturbing initial conditions and selected forecast model components such as convection.

Météo-France operates a global model, namely ARPEGE (Action de Recherche Petite Echèlle Grande Echèlle) and its deterministic forecast extends to 4 days ahead. Forecasts are computed on a stretched grid with higher resolution over Europe $(10 \mathrm{~km})$ and coarser resolution at the antipodes $(60 \mathrm{~km})$. Four $4 \mathrm{D}$-Var assimilations per day are performed over $6 \mathrm{~h}$ time windows. A convective-scale model is coupled to ARPEGE: AROME (Applications of Research to Operations at Mesoscale) is a non-hydrostatic model with a $2.5 \mathrm{~km}$ mesh on a $750 \times 720$ gridpoint domain centred over France. AROME deterministic forecasts range up to $30 \mathrm{~h}$ ahead and eight 3D-Var assimilations over $3 \mathrm{~h}$ time windows are performed each day, which use radar reflectivities and radial winds, among other data. In addition to these deterministic models, Météo-France also operates an ensemble prediction system using 35 members at a horizontal resolution varying from $15 \mathrm{~km}$ over Europe to $90 \mathrm{~km}$ at the antipodes, up to $108 \mathrm{~h}$ ahead. An ensemble data assimilation system of six members is also run operationally, at a regular horizontal resolution of $50 \mathrm{~km}$. It provides the deterministic ARPEGE assimilation with backgrounderror variance maps for the 'errors of the day' and the ensemble prediction system with perturbations for its initial conditions.

Environment Canada (EC) runs a global deterministic NWP system four times a day. The analysis is performed using a $4 \mathrm{D}-$ Var approach to provide the Global Environmental Multiscale (GEM) model (Côté et al., 1998) with initial conditions. Table I gives details on the model configuration and assimilation procedures. A regional model is also used to perform short-term integrations ( $48 \mathrm{~h})$, mostly for precipitation forecasts. The current operational version is based on a variable-resolution grid and should be upgraded soon to a limited-area version. The regional analysis is performed using a 3D-Var approach (Fillion et al., 2010). An Ensemble Kalman Filter (EnKF) with 96 members is also used to perform ensemble forecasts.

The Japan Meteorological Agency (JMA) operates two deterministic NWP systems, namely the Global Spectral Model (GSM) and the Mesoscale Model (MSM). The target of the GSM is short and medium-range forecasts up to nine days ahead. The model is routinely operated four times a day to produce the global forecasts. GSM outputs are used not only for weather forecast guidance but also for various other applications such as the generation of boundary conditions for MSM, the forcing of the ocean wave forecast model, volcanic ash tracer modelling, etc. The objective of the MSM is to provide guidance for issuing warnings or veryshort-range forecasts of precipitation covering Japan and its surrounding areas. The model is routinely operated eight times a day to produce rapid updated rainfall forecasts up to $33 \mathrm{~h}$. An incremental 4D-Var method is employed for both global and regional data assimilation systems.

NOAA's National Centers for Environmental Prediction (NCEP) run a daily suite of global and regional models developed largely at the NCEP Environmental Modeling Center (EMC). The Global Forecast System (GFS) model runs four times a day and produces forecasts at ranges up to 16 days, with decreasing spatial and temporal resolution over time. The North American Mesoscale (NAM) forecast system is one of the primary vehicles by which NCEP provides short-range guidance to public and private sector meteorologists. It is run four times daily at 0000, 0600, 1200, and 1800 UTC. The GFS model is initialized with Gridpoint Statistical Interpolation (GSI) analyses every $6 \mathrm{~h}$ and with a $6 \mathrm{~h}$ time window. The GSI is a 3D-Var data analysis system which was operationally implemented in May 2007. The NAM is initialized with a $12 \mathrm{~h}$ run of the NAM Data Assimilation System, which runs a sequence of four GSI analyses and 3-hour Weather Research and Forecasting Non-hydrostatic Mesoscale Model (WRF-NMM) forecasts using all available observations to provide a first guess to the NAM 'on-time' analysis

At the European Centre for Medium-range Weather Forecasts (ECMWF), two medium-range forecasts are produced each day with the Integrated Forecasting System (IFS), which are initialized with analyses from an incremental 4D-Var system. Linearized moist physics parametrizations are active during all stages of the innerloop minimization. The current moisture control variable is normalized relative humidity $(\mathrm{RH})$ and its extension to include cloud condensate is in preparation. The 10-day medium-range forecast is complemented by 51 -member ensemble prediction system that is extended to the monthly range once a week with reduced spatial resolution and by activating an ocean model component. The high-resolution $(16 \mathrm{~km})$ deterministic model is coupled with a wave model.

\section{Assimilation of clouds and precipitation}

\subsection{Derived products}

The main parts of this article are concerned with the assimilation of passive satellite radiometer observations; however, most operational centres actually assimilate ground-based rainfall observations and/or radar reflectivity and selected cloud products in their regional modelling systems. For example, regional models at the Met Office (NAE and UK4, UK1.5) assimilate cloud fraction and height through 4D-Var (NAE) and 3D-Var (UK4, UK1.5), as described by Renshaw and Francis (2011). The cloud is diagnosed from Meteosat Spinning Enhanced Visible and Infrared Imager (SEVIRI) imagery and also from surface reports (Taylor et al., 2008). The cloud fraction is converted to a RH and assimilated as such. Overall there are benefits seen to verification scores of cloud cover and screen-level 
temperature in the first $12 \mathrm{~h}$ of the forecast (Taylor et al., 2008). However, Renshaw and Francis (2011) detail the particular care that is needed to avoid degrading a forecast by adding or removing moisture at the wrong vertical level.

The Met Office also introduced the assimilation of radarderived rainfall data into its operational mesoscale model in 1996. The rainfall assimilation technique used is latent heat nudging (LHN; Jones and Macpherson, 1997). The same technique is still used operationally in the NAE model (gridlength $12 \mathrm{~km}$ ) and the UK4 and UK1.5 models. The surface precipitation rate estimates are supplied by a radar preprocessing step incorporating anaprop removal, bright band correction, orographic enhancement and regular adjustment with rain gauges. The weight given to rainfall rates during assimilation depends on distance from the nearest radar and beam height above freezing level.

Further experience with this LHN scheme was reported by Macpherson (2001) and Harrison et al. (2008). On a monthly time-scale, beneficial impact of LHN on precipitation forecast skill can be detected at a forecast range of $12 \mathrm{~h}$ in some months, while in other months a neutral signal is obtained. Increasing the frequency of the radar data assimilated from 3-hourly to hourly improves the first $6 \mathrm{~h}$ of the forecast. One observation impact study (Anderson, 2002) examined forecasts in which observations had given a significant improvement in 6-12 h rainfall forecasts, and investigated the origin of the improvement. Radar data were found to be the most frequent source of the benefit with a similar frequency for other data types such as aircraft and radiosonde. Recently, a variational assimilation of rain rate data has been developed and tested within the NAE $4 \mathrm{D}$-Var assimilation scheme, but this is not yet operational. Development of schemes to assimilate radar reflectivity has also started.

At Météo-France, reflectivity data from the 24 ground radar network have been operationally assimilated in the AROME analysis through a $1 \mathrm{D}+3 \mathrm{D}-\mathrm{Var}$ technique since April 2010. Pseudo-observations of $\mathrm{RH}$ are first retrieved from observed reflectivity vertical profiles through a $1 \mathrm{D}$ Bayesian retrieval. Then they are assimilated together with other observations in the AROME 3D-Var. The motivation behind this choice lies in the vantage position of AROME $3 \mathrm{D}-$ Var as a multivariate analysis scheme, together with the prospect of treating all the observations within a single system.

However, a straightforward assimilation of reflectivity data raises technical as well as scientific difficulties. Among these are:

(i) hydrometeor-related variables need to be included in the AROME 3D-Var control variable, which implies the computation of appropriate background-error statistics;

(ii) the tangent-linear of the observation operator for reflectivity and its adjoint must be coded; since the observation operator for reflectivity is nonlinear (threshold for detection of precipitation), this can entail sub-optimalities during the minimization process; and

(iii) the 'no-rain' issue (Lopez and Bauer, 2007; Errico et al., 2007) bars taking into account non-rainy observations and model equivalents; this is a major drawback since no rainy profiles can be produced when the model equivalent is non-rainy.
Since humidity is one of the most crucial parameters to initialize at convection scale (Ducrocq et al., 2002), it was decided to retrieve it in the same way as in Marécal and Mahfouf (2002). However, to avoid the above-listed drawbacks, the choice was made to use an alternative method to the 1D-Var, based on the Goddard profiling algorithm (GPROF) used to retrieve precipitation rates (Kummerow et al., 2001) from satellite observations, together with a database of Goddard cumulus ensemble simulations. The database consists of ordered pairs of vertical profiles of RH and reflectivity fields (built with a reflectivity observation operator using the prognostic hydrometeor variables) drawn from the model background vector state, in the vicinity of the observation location. The assimilation method was assessed on a number of cases, both in an idealized framework (observing system simulation experiments) and with real data (Caumont et al., 2010).

Studies with the AROME model on precipitating systems and the assimilation of volumetric radar reflectivities from the French ARAMIS (Application Radar à la Météorologie Infra-Synoptique) network resulted in a better description for short-term precipitation forecasts, qualitatively and quantitatively (mainly in 3-9 h forecasts), especially for cases of good vertical sampling of the atmosphere (Wattrelot et al., 2008). This method proved the capability to create proper increments to adjust the model reflectivities towards the observations, even if there is no rain (at the same location) in the model background fields. Indeed, the signal is always precipitation-sensitive. An indirect consequence of this is the possibility to use the 'no-rain' signal in order to dry and shift misplaced precipitating patterns in the model (Wattrelot, 2009). This highly enticing behaviour is rendered possible after a radar data pre-processing, leading to separate removed data (anaprop, sea or ground clutter) from the signal below a radar detection threshold (low signal-to-noise ratio).

At JMA, hourly precipitation data derived from groundbased radar observations over Japan have been assimilated operationally in the JMA MSM analysis since 2002. Raingauge observations are employed to calibrate the radar data and to produce the analyzed hourly precipitation estimates. The analyzed precipitation data are averaged and smoothed to fit the resolution of the $4 \mathrm{D}$-Var inner-loop model. A cost function of precipitation is devised by assuming an exponential error distribution (Koizumi et al., 2005). An improvement of model rainfall forecast spin-up was found when these data were assimilated.

In the JMA mesoscale modelling system, precipitation data derived from satellite microwave imager brightness temperatures were incorporated for the Special Sensor Microwave/Imager (SSM/I) and Tropical Rainfall Measuring Mission (TRMM) Microwave Imager (TMI) in 2003 and Advanced Microwave Scanning Radiometer (AMSR-E) in 2004 , in addition to the analyzed hourly ground-based radar precipitation data. Total column water vapour (TCWV) derived from microwave imager data is assimilated in clearsky conditions and derived precipitation is utilized in rainy conditions, which means that measurements of microwave imager data are assimilated under all weather conditions through retrieved quantities. It was found that the assimilation of microwave imager retrievals produces realistic atmospheric moisture fields which lead to better rainfall forecasts (Tauchi et al., 2004). 
At NCEP, simplified methods to assimilate radar reflectivity in regional analyses are under development and this effort will be extended to assimilate the data in a hybrid ensemble system that is a combination of variational and ensemble analyses planned for future implementation.

The National Oceanic and Atmospheric Administration (NOAA) has also implemented hourly updated data assimilation cycles, both with direct non-variational assimilation of cloud (METAR ceiling, visibility, current weather, cloud products derived from the Geostationary Operational Environmental Satellite, GOES), 3D radar reflectivity and lightning. These techniques were initially developed within the operational Rapid Update Cycle (RUC; Benjamin et al., 2004a, 2010). They have also been transferred into the Rapid Refresh (RR) planned to replace the RUC model in late 2011 (Benjamin et al., 2007), which is based on the NCEP GSI (Wu et al., 2002) analysis and the Advanced Research WRF (WRF-ARW; Skamarock et al., 2005) model. The RUC/RR cloud analysis package complements the variational data assimilation of moisture with a non-variational 3D updating of hydrometeors (cloud water, ice) with cloud information derived from METAR observations and cloud retrievals from GOES satellite instruments (Benjamin et al., 2004b) to improve short-range cloud forecasts. Assimilation of $3 \mathrm{D}$ radar reflectivity and lightning data (Weygandt et al., 2008) is performed by specification of estimated $3 \mathrm{D}$ latent heating within a digital filter initialization (DFI) already applied for $1 \mathrm{~h}$ cycling within both the RUC model and more recently, the ARW-WRF model. Adding the radar-LH to DFI is successful in improving $1-8 \mathrm{~h}$ convective and stable precipitation forecasts, both at $13 \mathrm{~km}$ resolution in the RR and RUC and also in a $3 \mathrm{~km}$ hourly updated model called the High-Resolution Rapid Refresh (HRRR).

ECMWF has performed various feasibility studies to investigate the potential of assimilating ground-based rainfall radar observations in the global 4D-Var system, either through the intermediate 1D-Var retrieval of TCWV using radar rainfall and the subsequent assimilation of TCWV in 4D-Var (Lopez and Bauer, 2007; Lopez et al., 2007), or through the direct assimilation of the radar observations in 4D-Var (Lopez, 2011). It was found that short-range forecasts of rainfall could be improved but with weaker impact on large-scale dynamics. In the 4D-Var system, the assimilation of $6 \mathrm{~h}$ rainfall accumulations proved to be superior to hourly rainfall due to more consistent observation-minusbackground statistics and the enhanced sensitivity of 4D-Var for accumulated rain over the $12 \mathrm{~h}$ assimilation window.

The emphasis of the above rainfall assimilation efforts is on regional applications; this is due to the fast dissipation of rainfall information through the forecast that was found in all systems, and the consistently high update frequency required for the resulting products. For global data assimilation, larger dimensioned radar networks, e.g. over the USA or Europe, are required to produce noticeable impact. As described, short-range forecasting is also supported by various satellite-based cloud imagery products that have not yet been tested in global and variational data assimilation systems.

\subsection{Infrared radiances}

Since advanced infrared sounders on polar orbiting satellites became available, infrared radiance $(15.5-3.7 \mu \mathrm{m})$ observations from these radiometers have provided the bulk of the observational information on clear-sky temperature and moisture in global data assimilation systems. Both the Advanced Infrared Radiation Sounder (AIRS; since 2002) and Infrared Atmospheric Sounding Interferometer (IASI; since 2006) are used fairly consistently across operational NWP centres in terms of channel selection, data screening and impact (Collard and McNally, 2009). The clear-sky data usage implies that model radiances are obviously restricted to the clear part of the atmosphere, and it thus requires cloud detection in the observations to prevent cloud contributions to the radiances being aliased into temperature and moisture analyses (McNally and Watts, 2003; Garand et al., 2007, 2011).

Recently, efforts to include cloud-affected data have been made to enhance global data usage in areas where forecasts are rather sensitive to the initial conditions (McNally, 2002). The main limitation here is the large nonlinear sensitivity of infrared radiances to cloud fraction and cloud-top height that can cause minimization failure in variational data assimilation systems.

Most of these approaches have been designed as extensions of the operational set-up for the assimilation of clear radiances and clear fields of view. A simplified cloud model is used by most centres. The effect of cloud on radiances is modelled by the effect of a mono-layered cloud located at a given cloud-top pressure $p_{\text {cld }}$. This effective cloud is semi-transparent with transmittance $\tau$ and covers a geometric fraction $N$ (between 0 and 1) of the field of view. The geometric fraction is not to be confused with the model's prognostic cloud fraction since it is retrieved from observations and refers to the simplified single-layer cloud assumption. The equivalent emissivity is therefore $N(1-\tau)=N \epsilon$, with cloud layer emissivity 'epsilon', and the cloudy radiance $L_{\mathrm{cld}}$ is given by a linear combination of the clear radiance $L_{\mathrm{clr}}$ and of the radiance corresponding to an overcast cloud at cloud-top pressure $L_{\mathrm{cld}, \mathrm{o}}\left(p_{\mathrm{cld}}\right)$ :

$$
L_{\mathrm{cld}}=L_{\mathrm{clr}}(1-N \epsilon)+L_{\mathrm{cld}, \mathrm{o}}\left(p_{\mathrm{cld}}\right) N \epsilon \text {, }
$$

where $L$ and $\epsilon$ are wavelength dependent.

The interpretation of the model given by Eq. (1) is not without some problems. The first problem is that there is always significant ambiguity between the two parameters. For example, an underestimated cloud-top pressure (cloud too high) can always be partly compensated for by decreasing the effective emissivity and vice versa. The use of multiple channels should in principle reduce this ambiguity, but the assumption of wavelength-independent $N \epsilon$ is only valid if the employed channels are spectrally close to each other (for example all located in the $15 \mu \mathrm{m} \mathrm{CO}_{2}$ absorption band) or if the cloud covers the entire field of view and is very thick.

The quality of the cloud parameters also depends on the type of cloud. Low clouds are always difficult to detect and to characterize from observations in the infrared range due to large surface emission contributions to the radiance signal and small temperature gradients across the boundary layer. Very thin clouds and multi-layered clouds produce ambiguities due to the contribution of deeper atmospheric layers to the total radiance (Pavelin et al., 2008). These authors also show that cloud-top pressure retrieval accuracy improves with increasing cloud fraction (their Figure 2).

In practice, the quantities $p_{\text {cld }}$ and $N \epsilon$ are thus effective 'catch-all' quantities that are used to explain the observed cloudy radiance in terms of a linear combination of a clear 
radiance and a cloudy radiance. $N \epsilon$ cannot be interpreted as the product of a geometrical cloud fraction and a physically meaningful emissivity. Likewise, $p_{\text {cld }}$ does not correspond to a physical cloud top. The simplified cloud parameters (that are generally estimated from the observations on their respective pixel geometry) incorporate any heterogeneity and nonlinearity in the real cloud properties. In certain conditions-e.g. when the true cloud is opaque and overcast with a homogeneous cloud height-the effective parameters take on a more physical meaning and can be compared to physical values from e.g. an NWP model.

The main advantage of Eq. (1) is its simplicity. It is therefore possible to model the cloudy radiances using a small number of effective parameters (at least two). $N \epsilon$ is generally extracted from the observed infrared radiances and not from the model cloud fields. This is because the often significant discrepancy between modelled and observed cloud locations and states can produce large radiance departures implying strong nonlinear model sensitivies.

At ECMWF, this situation has been acknowledged by strictly limiting the cloud-affected data usage to overcast scenes $(N=1)$ for which it is assumed that the infrared emissivity $\epsilon=1$ and thus $N \epsilon=1$. In these cases, the cloudtop pressure is retrieved fairly well from selected window channels, thus providing an anchor or linearization point for the minimization. As mentioned above, the limitation to overcast clouds also allows Eq. (1) to be interpreted more physically and compared to NWP model clouds.

The overcast option adds about $5 \%$ to data globally. The radiance calculations are then performed as in clear skies above the cloud and a fully opaque cloud deck is added as the lower-boundary condition (McNally, 2009). At Météo-France and EC, a similar window-channel retrieval is employed to obtain $N \epsilon$. However, the current experimentation is not limited to overcast situations. At both ECMWF and EC, cloud-top pressure (for EC also $N \epsilon$ ) can vary in the minimization but does not actively modify the actual cloud state. However, McNally (2009) shows that the differences between initial and final cloud-top pressure before and after minimization are rather small for overcast clouds-mostly less than $2 \mathrm{hPa}$ for low clouds and slightly larger for high clouds.

Pavelin et al. (2008) describe how at the Met Office 1DVar is used to retrieve cloud-top pressure and effective cloud emissivity from AIRS and IASI radiances. These cloud parameters are then passed onto $4 \mathrm{D}-$ Var and kept constant for use in the radiative transfer model calculating radiances. This allows 4D-Var to use cloud-affected radiances, although the cloud information itself is not assimilated. 1D-Var experiments of this kind have also been performed by Heilliette and Garand (2007) at EC.

The performance of a simple one-layer cloud scheme, as described in Eq. (1), only constrained by cloud-top height and cloud fraction, has also been investigated by JMA. It was confirmed that, although the cloud height is often overestimated for clouds with small fractional coverage, this method becomes quite reliable and it significantly reduces observation-minus-model departures for cloud fractions above 0.8. 1D-Var experiments with a simple cloud scheme have been carried out under almost overcast conditions at JMA, similar to those at the Met Office. Preliminary results show that once cloud-affected channels are added, as expected, sharper analysis increments of temperature at the cloud top and additional temperature and humidity increments below cloud base are generated when compared to a clear-sky radiance $1 \mathrm{D}-\mathrm{Var}$.

Auligné (2007) proposed an alternative to this singlelayer cloud formulation called the Multi-variate Minimum Residual (MMR). The cloud-top height and cloud fraction (or effective emissivity) in Eq. (1) are simply replaced by an array of cloud fractions for each model vertical level. This formulation allows for thick clouds and multiple cloud layers. Since clouds at every vertical level are assumed to be opaque, the effective cloud fraction retrieved by the MMR scheme corresponds to the cloud amount within the portion of the instrument pixel which is not covered by clouds above. Therefore, the sum of all the cloud fractions plus the clear fraction is always equal to 1 . This simplified formulation alleviates the difficult issue of cloud overlap.

For feasibility testing, the scheme has been implemented in ECMWF's IFS, NCAR's WRF and NCEP's GSI data assimilation systems, using either Radiative Transfer for TOVS (RTTOV) or Community Radiative Transfer Model (CRTM) forward models. Figure 1 compares the retrieved cloud-top pressure from the NASA AIRS and the Moderate Resolution Imaging Spectroradiometer (MODIS) Level 2 product for a single granule over the high southern latitudes (where clouds are usually harder to detect). The consistency of the cloud information among the AIRS pixels demonstrates the robustness of the scheme, since independent retrievals are performed for every pixel. The fair agreement with the MODIS products shows the skills of the MMR scheme to select the cloud-free observations. Furthermore, the retrieved cloud fractions can be used to form a simple linear observation operator and the resulting observation-minus-background departures are in fact comparable to the cloud-free ones for nearly all pixels. The impact of such a scheme on the analysis remains to be demonstrated.

JMA is also studying the assimilation of cloudy infrared radiances including all model cloud variables. Similar cloud liquid (ice) water and cloud fraction model first-guess profiles are produced when either the parametrization based on Smith (1990) or the diagnostic scheme of Tompkins and Janisková (2004) are used. While observation-minusmodel first-guess departures at thermal wavelength channels become smaller by including the effect of clouds (accounting for scattering through use of RTTOV), they still exhibit large negative values for deep clouds due to insufficiently modelled cloud absorption. For short-wave infrared channels, firstguess departures are overall slightly negative, most likely because not only cloud scattering and absorption but also gas absorption is not adequately modelled. It was found that nonlinearity increases with the number of cloud variables perturbed once cloud water profiles and cloud fraction have been added.

Given the individual results produced at all NWP centres, the grey cloud formulation seems to represent a possible option given the quality of currently available cloud parametrization, but the linearity constraint in global data assimilation systems may require its limitation to fractional cloud coverage close to 1 . More sophisticated schemes like the MMR promise to add information on vertical layering and the method is already being tested within existing NWP systems.

In general, the main impact of the additional cloudaffected data is to produce temperature weighting functions at cloud top that are much sharper than in clear-sky 
(a)

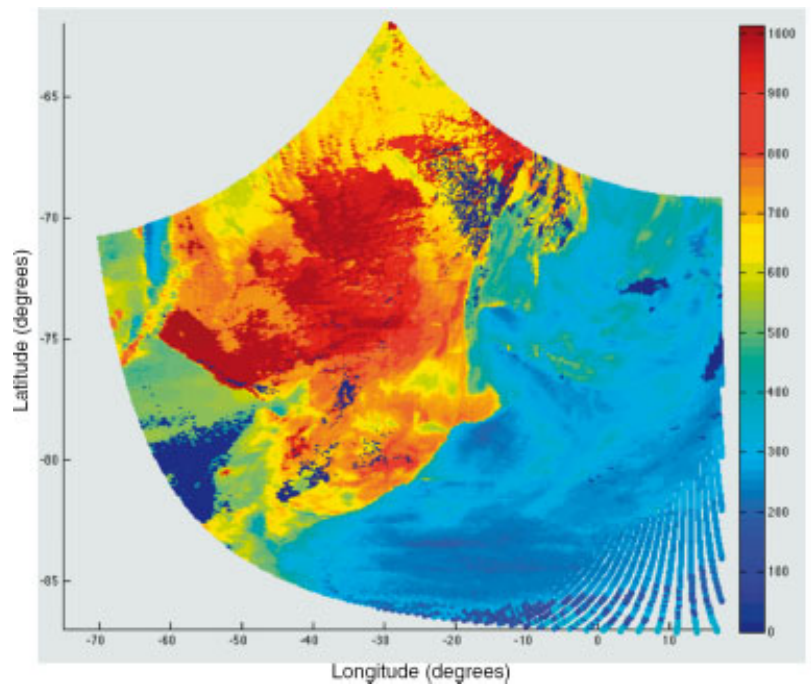

(b)

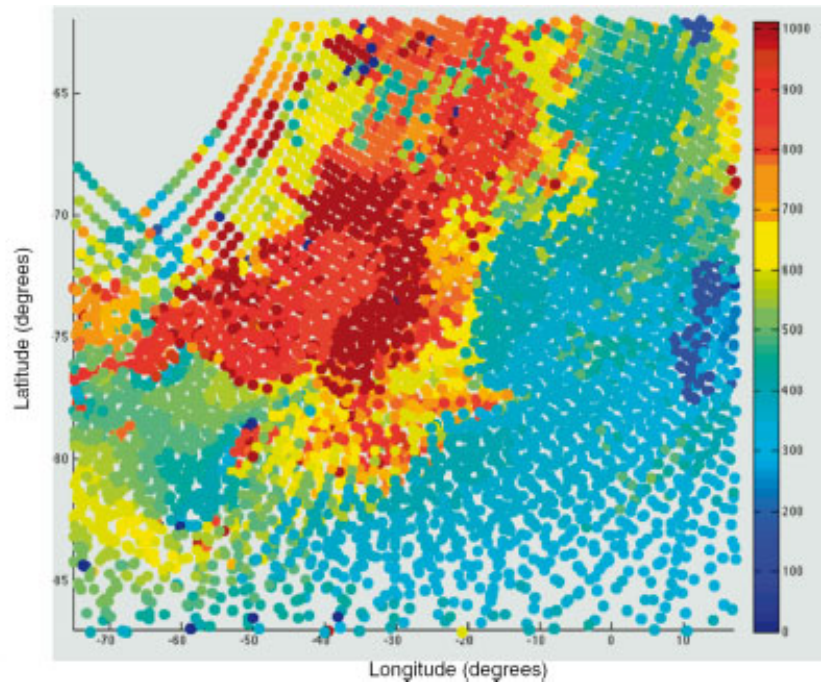

Figure 1. Cloud-top pressure (hPa) derived from (a) Aqua MODIS and (b) AIRS using the NCAR Multi-variate Minimum Residual (MMR) method. This figure is available in colour online at wileyonlinelibrary.com/journal/qj

conditions, even for low-level clouds for which unknown surface emission effects can become problematic in clear skies. In addition, channels whose weighting functions peak above clouds but still receive significant cloud contributions can be used more aggressively to gain extra information on temperature and humidity above the cloud that would otherwise be excluded.

Note that all the above experiments and implementations do not actively account for spatial representativeness issues such as the mismatch between spatial sampling and resolution provided by infrared radiometers and the actual skill of NWP models to represent clouds at the right location and with the correct extent and overlap.

Figure 2 shows the most significant impact of cloudaffected infrared radiance data assimilated through the model in Eq. (1) in the ECMWF, Météo-France and EC analyses. The impact is illustrated by the mean change of temperature at lower levels, i.e. 700 and $850 \mathrm{hPa}$. Generally, the cloud-affected data increases temperatures at $700 \mathrm{hPa}$ and decreases temperatures at $850 \mathrm{hPa}$ (and thus decreases lapse rate) in subtropical areas with significant presence of stratocumulus in all systems. The cloud tops are typically just below $850 \mathrm{hPa}$, so the impact here comes directly from the sensitivity to temperature at the cloud top.

The main features of these mean differences are reproduced by all systems, but the magnitude is much larger in the Météo-France and EC analyses because more data are used due to the inclusion of fractional cloud cover (note that the experiments were run over different periods). The significant differences between the magnitude of impact between centres may also demonstrate the above-mentioned ambiguity between cloud-top pressure and cloud fraction and indicate the risk of aliasing cloud retrieval errors into temperature analyses in the presence of clouds with small fractional coverage.

While the patterns of mean temperature impact shown in Figure 2 could simply indicate model biases, the fact that similar patterns are seen in all three systems might indicate something more fundamental, such as the shape of the radiance Jacobians, background-error correlations or physical model processes. The features of warming at $700 \mathrm{hPa}$ and cooling at $850 \mathrm{hPa}$, which are associated with areas of stratocumulus cloud, suggest a mechanism of cloud-topsensitive satellite observations producing sharp increments at the cloud top and further increments of opposite sign well above the boundary clouds. The latter cannot be the result of vertical model background-error correlations, i.e. a secondary effect of the temperature increments at $850 \mathrm{hPa}$, because temperature correlations are weak between layers and the vertical profile of background temperature error standard deviations is usually flat. Since vertical exchange processes are limited in these situations between the two levels, the shape of the radiance Jacobians could explain the dipole of analysis impact. This phenomenon requires further investigation.

In addition, both ECMWF and Météo-France systems also produce increments near the top of the troposphere associated with cirrus clouds. However, due to their small optical thickness and horizontal extent, the increments are largely limited to the Tropics.

Figure 3 illustrates the impact of adding cloud-affected AIRS/IASI radiance observations to the Met Office and Météo-France systems in terms of the relative change of forecast errors. For the Met Office (Figure 3(a)), 1-5 day root-mean-square (RMS) forecast error differences for mean sea-level pressure (PMSL), geopotential height at $500 \mathrm{hPa}$ (Z500), wind speed at 850 and $250 \mathrm{hPa}(W 850, W 250)$ over Northern and Southern Hemispheres ( $\mathrm{NH}$ and $\mathrm{SH}$ ) as well as Tropics (TR) show mostly improvements by up to $2 \%$. The impact tends to dissipate quickly into the forecast and the $\mathrm{SH}$ impact is mixed. The Météo-France results (Figure 3(b)) show a slightly weaker impact because only the impact of the additional IASI cloudy observations is shown since AIRS cloudy data are already contained in both cases. However, the general trend is very similar; again a small increase of SH geopotential height and wind errors is observed.

Future research needs to investigate the relationship between this degradation and the observations used in the presence of multi-layered clouds with $N \epsilon$ largely different from 1. Generally, McNally (2009) obtains a similar forecast impact in the ECMWF system, namely a marginally positive impact on $Z 500$ in $\mathrm{NH}$ and $\mathrm{SH}$ and a $1-2 \%$ positive impact on $700 \mathrm{hPa}$ temperatures at all latitudes, and no degradation 
(a)

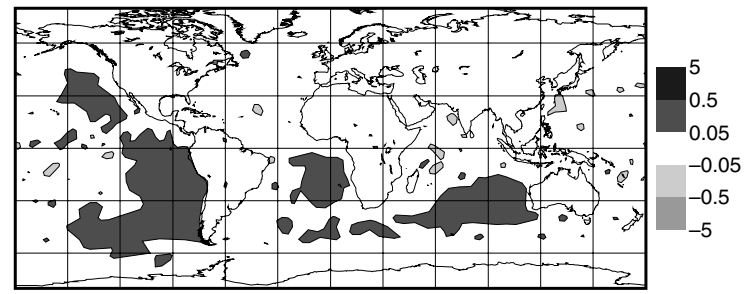

(b)

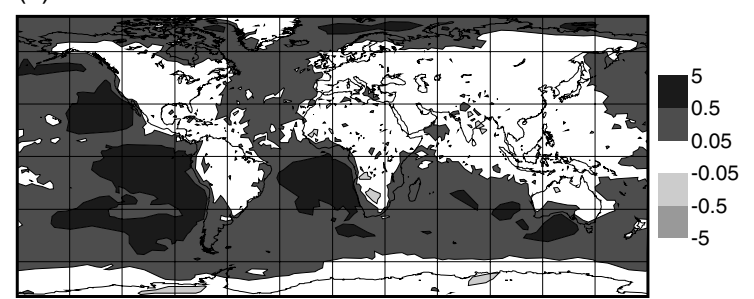

(c)

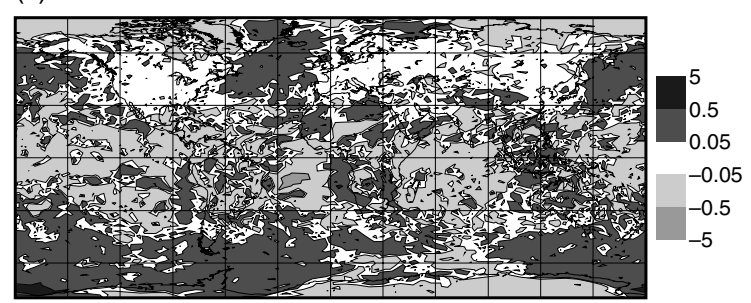

(d)

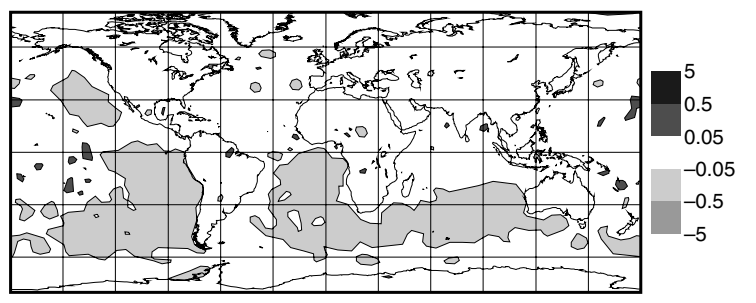

(e)

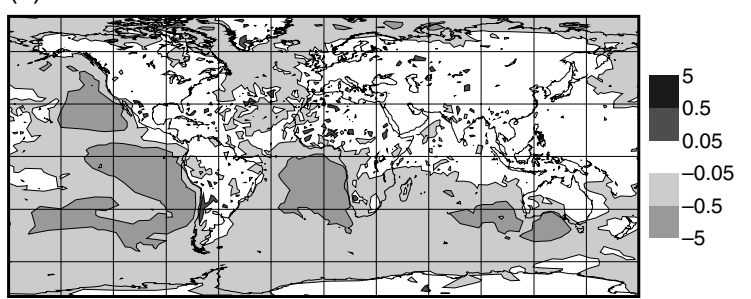

(f)

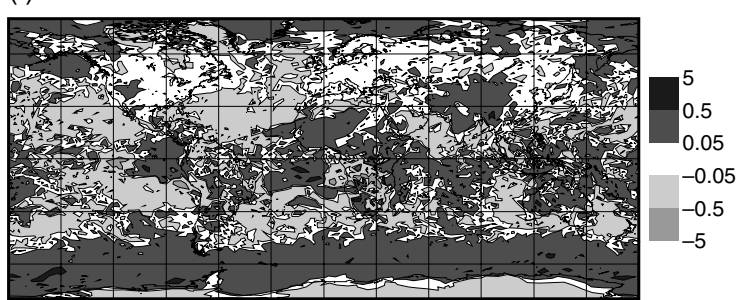

Figure 2. Mean temperature analysis impact (K) of cloud-affected infrared sounder radiance data (a, b, c) at $700 \mathrm{hPa}$ and (d, e, f) at $850 \mathrm{hPa}$ from (a, d) ECMWF, (b, e) Météo-France and (c, f) Environment Canada model experiments for periods September-November 2009 (ECMWF) and September 2010 (Météo-France and Environment Canada).

(a)

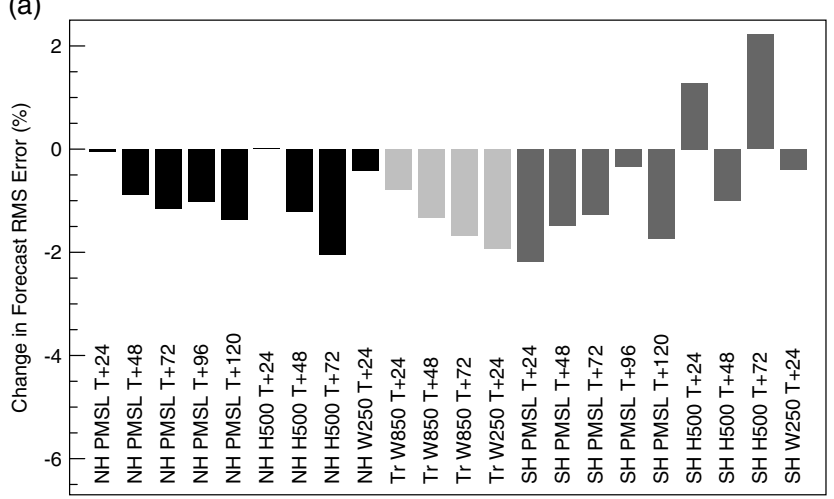

(b)

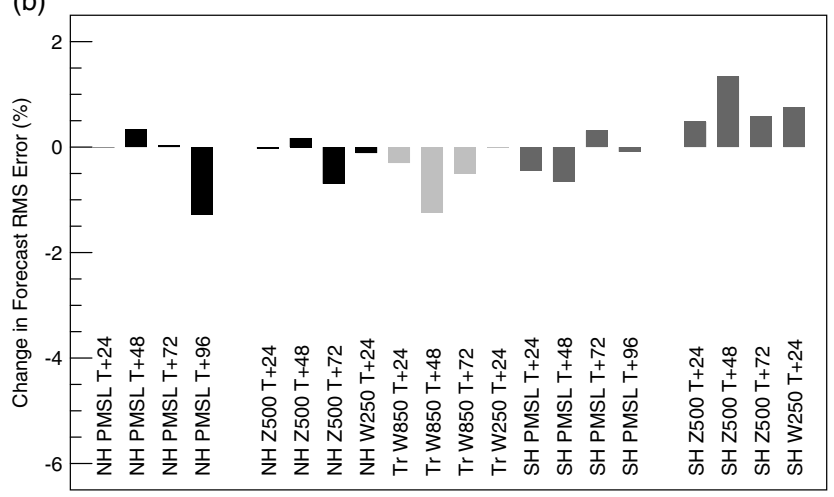

Figure 3. Relative change in root-mean-square forecast errors for selected parameters between clear + cloud-affected and clear-sky only infrared radiance data assimilation experiments in the (a) Met Office and (b) Météo-France systems for December 2008, verified against sonde, SYNOP and buoy observations.

in the SH. Given that only about 5\% more data are added, this impact is quite considerable and it seems to alleviate the $\mathrm{SH}$ forecast error increase.

The addition of infrared radiances affected by clouds mainly aims at a more aggressive use of temperature and moisture sounding information near the cloud top and, as described above, does not affect cloud parameters by construction. In fact, the experiments displayed in Figure 2 did not reveal an impact on cloud cover or other cloud parameters (not shown). The extent to which the single cloud layer approach can be widened to address multiple layer clouds and cloud fractions significantly different from 1 remains the subject of future research, but the above-mentioned nonlinearity issue may not permit a fully open system in global incremental 4D-Var.

Copyright (C) 2011 Royal Meteorological Society, Crown in the right of Canada, and British Crown copyright, the Met Office

\subsection{Microwave radiances}

\subsubsection{Microwave sounders}

Contrary to the infrared, microwave radiances are sensitive to the entire column of water vapour, cloud water/ice and precipitation as well as the surface. Microwave imagers mostly employ channels located in atmospheric absorption windows, thus maximizing the radiance sensitivity to cloud and the surface while sounders use channels near oxygen and water vapour absorption lines to maximize sensitivity to the atmospheric temperature and moisture profile. The sounders also include a few window-like channels used for cloud detection and surface property retrievals supporting the sounding application. 
The approach to using microwave imagers or sounders in the presence of clouds for NWP therefore differs in that imager data assimilation aims at adding information on humidity (mostly total column), cloud, precipitation and surface wind to the analysis over oceans, while sounder data assimilation aims at producing a cleaner temperature and moisture profile analysis over both land and oceans. The latter is very similar to cloud-affected infrared radiance assimilation and is expected to have little direct impact on the clouds themselves. However, microwave radiances lack the same strong sensitivity to cloud-top pressure and fractional cloud cover at cloud top, but rather respond to integrated column cloud properties. This also implies a much smaller degree of nonlinearity than present for infrared radiances, and thus a much lower need to linearize the minimization problem near an observed cloud retrieval such as $N \epsilon$.

It is generally assumed that microwave sounders are allweather instruments, but cloud liquid water absorption is rather efficient at frequencies above $50 \mathrm{GHz}$, so that even sounder radiance assimilation would ideally include the effects of cloud and precipitation contributions to absorption and scattering to fully comprehend their effect on the measured radiances. This requires moist physical parametrizations being accurate enough to produce model cloud and precipitation predictions that are close to the observations, and activated moist physics schemes in the minimization to provide a consistent clear and cloudy state update in the analysis.

At the Met Office, a priority has been set on improving the sounder radiance data usage and Advanced Microwave Sounding Unit (AMSU-A) radiances are used in 4D-Var in the presence of cloud liquid water, outside the Tropics (north of $20^{\circ} \mathrm{N}$ and south of $20^{\circ} \mathrm{S}$ ) and when scattering is not detected (Adrian Jupp, personal communication). AMSU-A channels 1 and $2(23.8$ and $31.4 \mathrm{GHz})$ are more sensitive to cloud liquid water than other AMSU-A oxygen band channels. The intention is that $4 \mathrm{D}-\mathrm{Var}$, by varying total $\mathrm{RH}$ (vapour plus cloud) to fit channels 1 and 2, will improve the use of the temperature sounding channels. At all other centres, both AMSU-A and Microwave Humidity Sounder (MHS) radiances are treated as clear-sky observations for which a cloud detection (usually based on thresholding first-guess departures) is applied to the observations, and the presence of clouds in the model atmosphere is ignored.

Figure 4 shows an example of Metop AMSU-A channel 4 radiance first-guess departure differences when cloud effects are neglected (Figure 4(a)) or included (Figure 4(b)) in the radiative transfer calculations at ECMWF. Until now, cloud contributions have been ignored in most systems and quality control algorithms are applied to the first-guess departures to avoid aliasing of cloud contributions into lower tropospheric temperature analyses. In this case, the areas of significant cloud absorption are highlighted by positive departures in Figure 4(a) since clear-sky radiative transfer calculations for this channel underestimate the atmospheric contribution added by relatively warm clouds over the radiometrically cold surface. Accounting for clouds greatly reduces the departures, except in areas where the model clouds and the radiative transfer model produce biases, and thus a much cleaner temperature analysis can be expected (Figure 4(b)). Note that the calculations are solely based on the ECMWF model clouds and do not involve additional cloud parameters retrieved from observations.
The same approach can be applied to AMSU-A channels $5-6$, but less improvement is obtained since the effect of clouds on these channels is mostly limited to areas where there are frozen hydrometeors in deep convective clouds. During these tests, it was found that it was important to interpolate model temperature profiles to the exact observation location to produce acceptable firstguess departures. This means that the strong sensitivity of microwave sounder radiances to temperature dominates the signal and that model temperature gradients between grid-boxes must be accounted for. This is less important for clouds for which larger model cloud location errors exist in the first place.

For both microwave and infrared sounders, the main priority at the Met Office and ECMWF is to produce a better atmospheric temperature analysis by performing more accurate radiative transfer calculations, rather than to affect the model moist physics parametrizations directly. The advantage of such a system is that only little modification needs to be applied to the existing data assimilation system, since only model first-guess clouds (produced by the shortrange forecast) and no active interaction with the model physics are required, so that control vector, backgrounderror statistics and linearized physics remain unaffected.

In the USA, the Joint Center for Satellite Data Assimilation (JCSDA) and the National Centers for Environmental Prediction (NCEP) have been working to assimilate cloudaffected microwave radiance data to improve the global analysis. It is planned to include AMSU-A radiance data affected by clouds over the ocean in the operational Global Data Assimilation System (GDAS) by 2012, and to move on to including cloud-affected microwave imager data afterwards. The observation errors as a function of the mean observed cloud amount and first-guess cloud amount have been estimated based on statistics of the first-guess departures for all-sky (i.e. clear and cloudy) radiances following Geer and Bauer (2010). For now, cloud water (liquid + ice) is being used as the control vector for all-sky radiance assimilation in addition to temperature, humidity, surface pressure, and surface winds, but total moisture (water vapour + cloud liquid + cloud ice + hydrometeors) as a control variable is currently being tested. The backgrounderror covariance matrix, in which error variances of cloud water are specified, are currently constructed by the NMC method. The background-error covariance from the hybrid ensemble approach will be tested following the GSI update from 3D-Var to a hybrid 3D-Var planned to be operational for early 2012.

The extension of moisture-based control variables to cloud variables is currently also being investigated at ECMWF. The most likely option will be to add cloud liquid water and cloud ice to the 'dry' control variables that are variance-normalized to produce Gaussian error covariance statistics as also employed for the moisture variable (Hólm et al., 2002). The Met Office system already employs a total water control variable (Table I) in both 4D-Var and 1D-Var systems.

\subsubsection{Microwave imagers}

Most operational NWP centres have been assimilating microwave imager data in clear skies for a long time, mainly to constrain lower tropospheric humidity over oceans (Table I). The identification of clear-sky areas is usually 


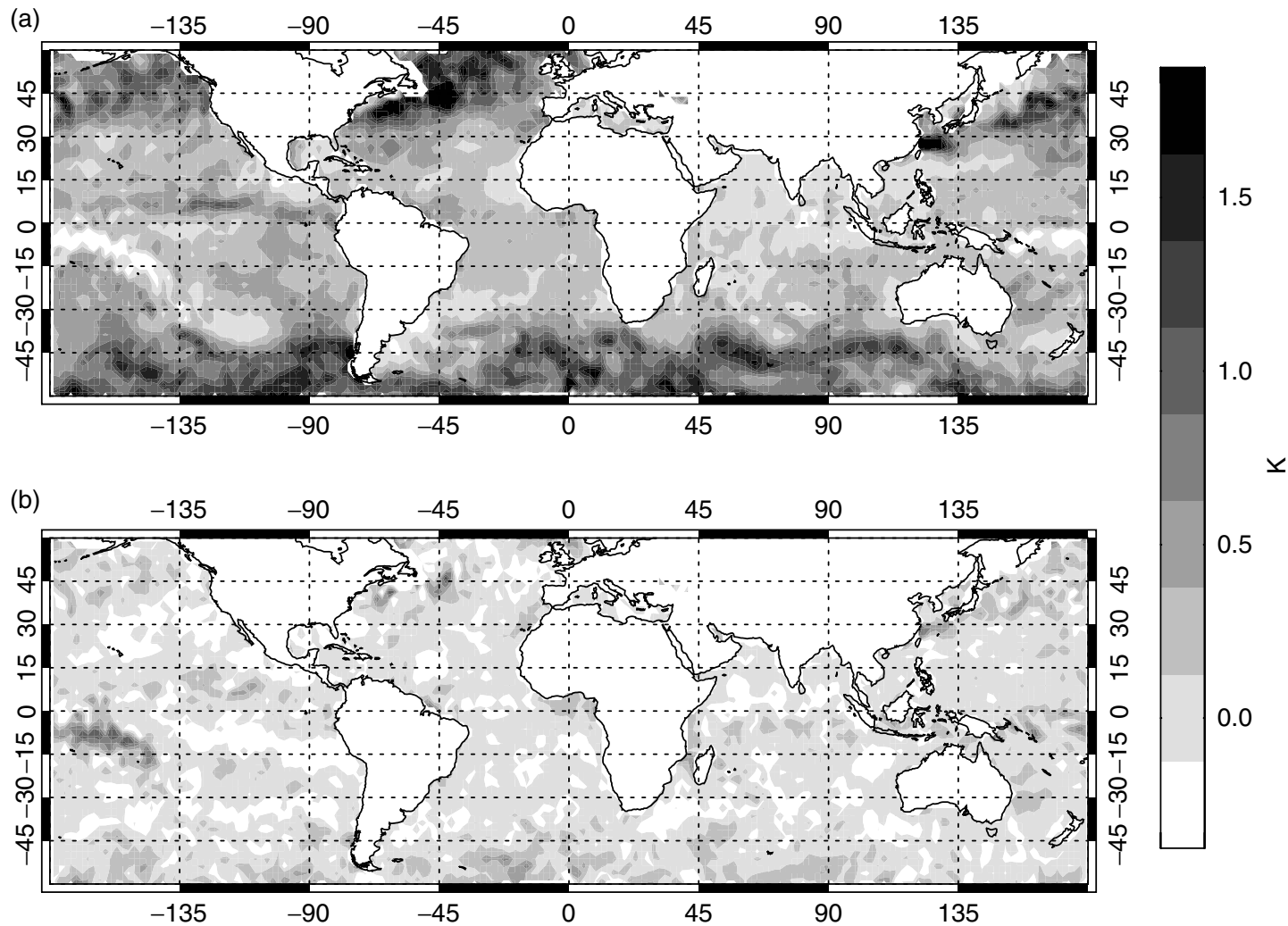

Figure 4. Mean first-guess departure difference (K) of Metop AMSU-A channel 4 radiances when model cloud effects are (a) ignored or (b) included in the radiative transfer calculations. The period is 1-8 February 2010.

based on the observations and by neglecting model clouds. Before the direct assimilation of radiances in 4D-Var, most centres experimented with 1D-Var algorithms to retrieve TCWV and near-surface wind speed over oceans to better understand the sensitivity of radiances to moisture regime and clouds, as well as to help characterize model biases and observation operator errors (e.g. Phalippou, 1996). The retrieved parameters from the $1 \mathrm{D}$-Var are then assimilated in $4 \mathrm{D}-$ Var, hence this approach is called $1 \mathrm{D}+4 \mathrm{D}-$ Var.

ECMWF assimilated SSM/I radiance data in this way between 1998 and 2002, after which the radiances were assimilated directly in 4D-Var until 2005. The same approach is shared by Météo-France since 2006 due to the common computer code; the Met Office is also assimilating TCWV and sea-surface wind speed retrieved from microwave imager radiances in clear skies. At EC, SSM/I observations are assimilated in clear-sky conditions-soon to be complemented by SSMIS observations. The JMA global analysis has used microwave radiance data under clearsky conditions since 2003 and the current system includes AMSR-E on Aqua, TMI on TRMM, and SSMIS on Defense Meteorological Satellites Program (DMSP) F-16 and F-17. Experiments at ECMWF have indicated that too many microwave imager observations may constrain the analysis too strongly and produce an overall detrimental impact. This is partly explained by significant model moisture biases, particularly in the Tropics. For this reason, JMA assigns rather large observation errors to the observations. This avoids excessive positive moisture increments and thus rainfall in the early stage of the forecast range due to the common dry model bias.

In clouds and precipitation, microwave imager data are mostly sensitive to the integrated path of liquid water and ice, moisture and surface wind depending on frequency, cloud cover and cloud depth. The observation operator thus becomes more complex because it requires running moist physics parametrizations and a multiple-scattering radiative transfer code with a more demanding definition of model biases, observation operator errors and data assimilation systems (e.g. Geer et al., 2010).

In 2005, ECMWF added cloud- and precipitation-affected microwave imager radiances to the clear-sky stream. The initial system was also based on a $1 \mathrm{D}+4 \mathrm{D}$-Var approach in which the 1D-Var retrieved TCWV in cloudy areas, which was subsequently assimilated in 4D-Var (Bauer et al., 2006a,b; Geer et al., 2008). The ECMWF 1D+4D-Var system was superseded in 2009 by the direct assimilation of radiances in 4D-Var, the so-called all-sky system (Bauer et al., 2010; Geer et al., 2010). The all-sky approach is the first fully open system in which no a priori distinction between clear or cloudy observations or model profiles is made and the adjustment of temperature, moisture, surface and cloud state is left to $4 \mathrm{D}-\mathrm{Var}$ and the involved physical parametrizations. The all-sky system has been further refined by an enhanced error formulation (Bormann et al., 2010; Cardinali and Prates, 2011; Geer and Bauer, 2010, 2011).

The above experience suggests that adding clouds and precipitation also adds many degrees of freedom and that NWP model cloud and precipitation biases in occurence, location and intensity quickly dominate the observation-minus-model departure statistics from which the observational information in data assimilation is drawn. Different parametrizations can produce substantially different observation simulations. For radiance assimilation, only a few multiple-scattering radiative transfer models are available that also include forward, tangent-linear and 
(a)

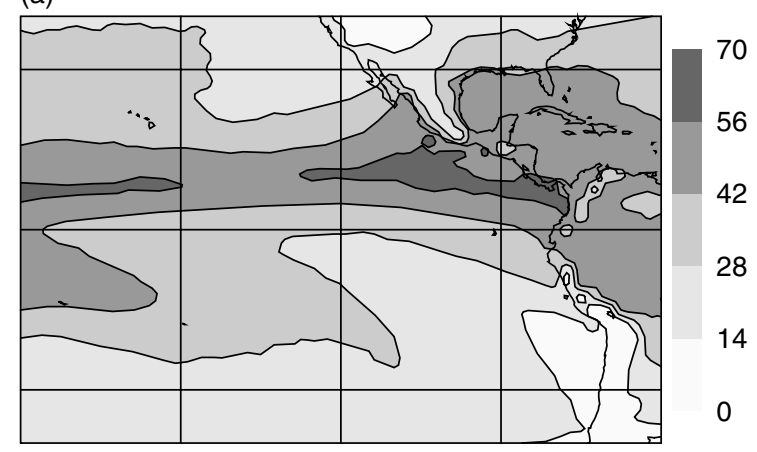

(c)

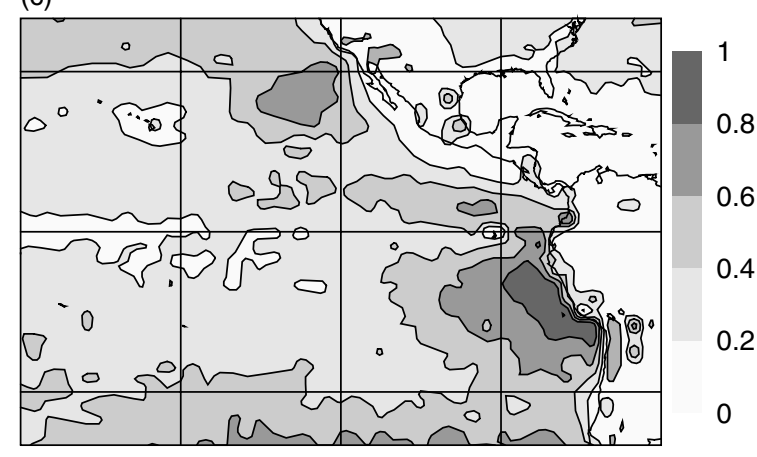

(b)

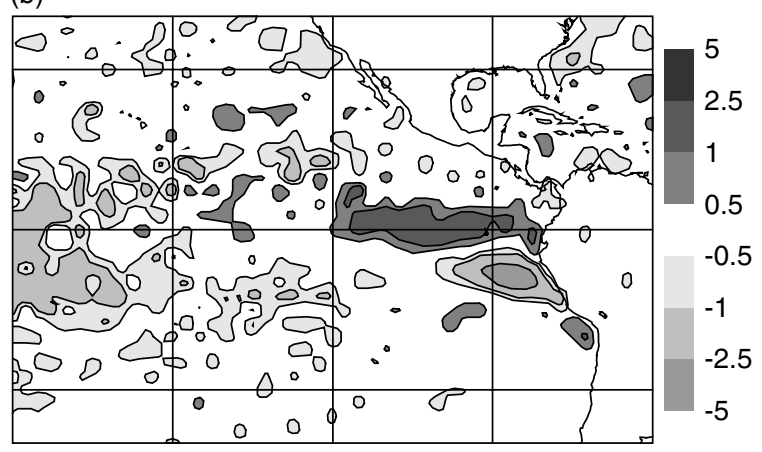

(d)

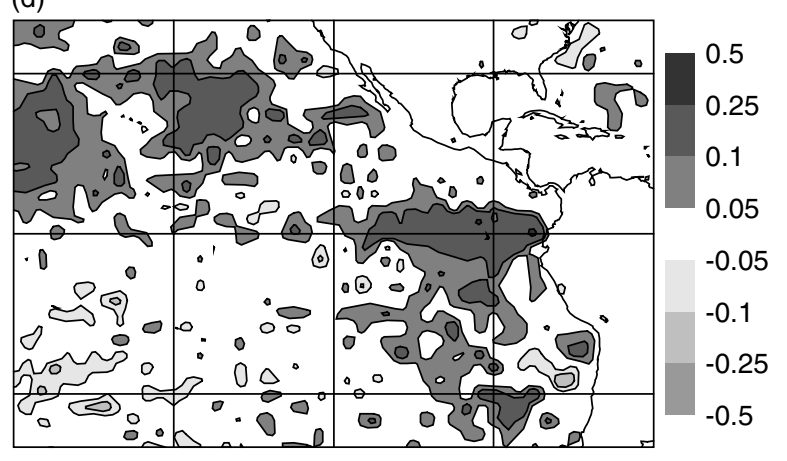

Figure 5. (a) mean TCWV analysis $\left(\mathrm{kg} \mathrm{m}^{-2}\right)$, (b) mean TCWV analysis difference between all-sky and no-microwave-imager experiments (kg m ${ }^{-2}$ ), (c) mean low cloud cover in analysis and (d) mean low cloud cover difference between all-sky and no-microwave-imager experiments, for period September-October 2009.

adjoint model versions and undergo rigorous testing and model updating to ensure their safe application within operational systems. Examples are RTTOV-SCATT and the Community Radiative Transfer Model (CRTM; Chen et al., 2008). Both models include forward, tangent-linear and adjoint model versions (also Bennartz and Greenwald, 2011).

\subsubsection{Experiments}

The general performance of the ECMWF all-sky system in analysis and forecasts has been widely documented. However, in the following, we will compare and contrast the impact on analyses of cloudy infrared radiances (also section 3.2) with that of cloudy microwave radiances using the ECMWF all-sky data assimilation system. The two observation types will be compared by showing their impact on mean analysis state and analysis increments for selected variables. Since a large diversity of observations are used in the analysis, the effect of overcast infrared and microwave radiances is isolated by analysis (increment) differences between experiments with and without the respective observation type, but by maintaining all other observations in the experiments.

The results presented in this section were derived from the following set of experiments:

(i) all-sky microwave plus overcast infrared radiances;

(ii) as (i) but withdrawing all-sky microwave radiances;

(iii) as (ii) but withdrawing overcast infrared radiances.

Therefore the comparison of (i) and (ii) allows the estimation of the impact of all-sky microwave radiances while the comparison of (ii) and (iii) allows the evaluation of the impact of overcast infrared radiances. The latter may become amplified by the absence of all-sky microwave radiances in (ii) and (iii) but the intention here is to show basic effects rather than to put different observation types in competition.

Figure 5 shows the mean analysis TCWV and low cloud cover (LCC) of the all-sky experiment, as well as the analysis differences between the all-sky system and the experiment in which all microwave imager data have been denied (nomicrowave-imager). In the eastern tropical Pacific, the main impact of microwave radiometer data is a moistening by up to $10 \%$ just south of the intertropical convergence zone (ITCZ) over warm waters and a drying off the coast of Peru where usually strong meridional sea-surface temperature (SST) gradients occur. These are caused by a rather steady anticyclonic circulation pattern located off the western coast of South America, which drives cold air northwards near the surface and produces oceanic upwelling. The location of the anticyclone in the downwelling branch of the Hadley circulation leads to consistent large-scale temperature inversions at the top of the boundary layer and persistent stratocumulus cloud decks. The impact of microwave imager data on TCWV is also translated into lowlevel cloud cover enhancements (Figure 5(d)). The cloud cover enhancement mostly occurs in the areas of moistening over the equatorial eastern Pacific, while the region with persistently high amounts of LCC remains unaffected due to moisture levels near saturation. Overcast infrared radiances, however, produce very little effect on moisture and cloudiness (not shown). This is partly due to the much smaller amount of infrared overcast compared to microwave radiance data but also because infrared overcast data mainly affect lower-level temperatures rather than moisture.

The mean analysis difference for temperature and horizontal wind at 700 and $850 \mathrm{hPa}$ is shown in Figure 6 for 
(a)
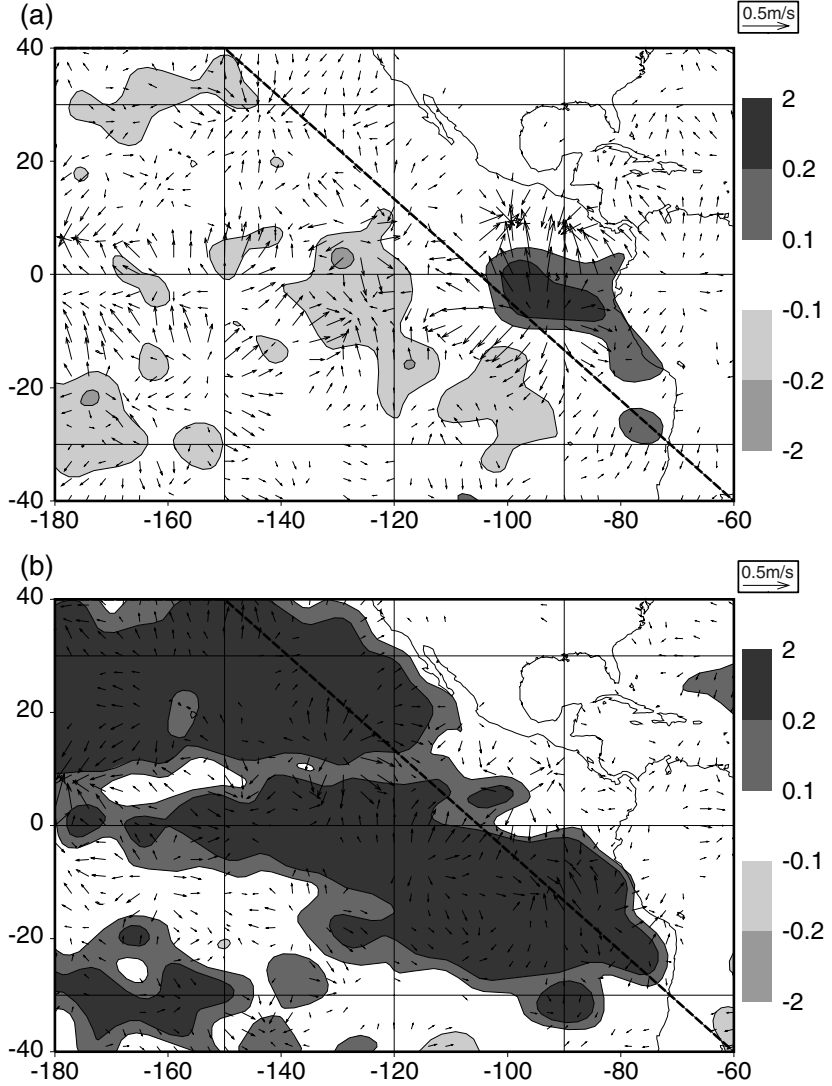

Figure 6. Mean (a) $700 \mathrm{hPa}$ and (b) $850 \mathrm{hPa}$ temperature (shading, K) and wind (arrows) analysis difference between all-sky and no-microwaveimager experiments. The period is September-October 2009. The dashed line shows the cross-section used in Figure 8.

microwave and in Figure 7 for infrared radiances. The cloudaffected infrared radiance assimilation is restricted to areas of overcast clouds depicted in Figure 5(c). As already described in section 3.2, the analysis differences (Figure 7(a) versus (b)) show a change of sign between $850 \mathrm{hPa}$ and above the clouds at $700 \mathrm{hPa}$. Since tropospheric temperature backgrounderror standard deviation functions are fairly constant with height in the ECMWF 4D-Var system, this shape is most likely the result of the sharpening of the infrared sounder weighting functions at cloud top that produce a cooling near the cloud top and a significant warming in the layers above. A similar shape of increments has been found by McNally (2009) for low-level clouds in the North Pacific (his Figure 5(a)). The dynamic response is not particularly strong since mean wind analysis differences remain below $0.3 \mathrm{~m} \mathrm{~s}^{-1}$. However, at $700 \mathrm{hPa}$ air is generally moved away from the area of warming while enhanced convergence is produced at $850 \mathrm{hPa}$.

Interestingly, the presence of all-sky microwave radiances produces a similar impact at $700 \mathrm{hPa}$ compared to overcast infrared radiances (Figure 6(a)) but a much more widespread opposite temperature increment at $850 \mathrm{hPa}$, also towards the north (Figure 6(b)). The general impact is stronger due to the much larger volume of microwave data that comprise clear and cloud-affected observations. The microwave radiometer weighting functions are also broader than those from infrared instruments and their main sensitivity is to moisture. The moisture sensitivity is roughly proportional to the moisture density profile, so that the greatest contribution comes from near (a)

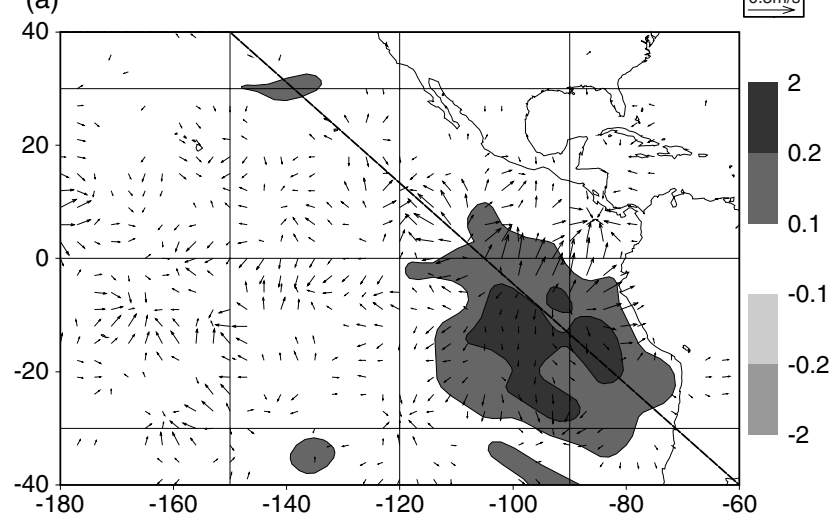

(b)

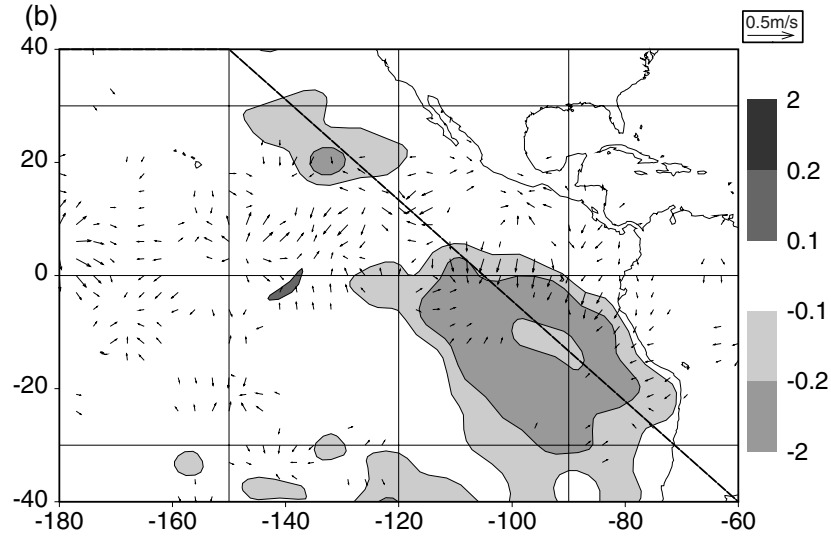

Figure 7. As Figure 6, but showing the mean impact of overcast infrared radiances.

the surface. For microwave radiance assimilation, the temperature increments are therefore a secondary effect coming either (i) through the transformation to the RH control variable, whose background-error standard deviations exhibit a pronounced peak near $850-800 \mathrm{hPa}$, or (ii) from cloud information and through the moist physics parametrisations. Thus similar and opposite impacts of infrared and microwave radiances on temperature are produced by very different mechanisms in the analysis, and exhibit some inconsistency at lower levels in this complex meteorological environment.

Figure 8 shows zonal cross-sections of temperature and $\mathrm{RH}$ increments along the line $\left(150-60^{\circ} \mathrm{W} / 40^{\circ} \mathrm{N}-40^{\circ} \mathrm{S}\right)$ overplotted on Figures 6 and 7. The line crosses the areas of maximum analysis difference and roughly tracks the direction of the strongest SST gradients. The southeastern end is co-located with the region of highest low-level cloud cover and the northwestern part crosses the ITCZ (at about $10^{\circ} \mathrm{N}$ ) into the trade-wind zone north of the ITCZ, again an area with higher amounts of low-level clouds. Mean increment differences are shown between the overcast infrared radiance data denial experiment and its control (Figure 8(a)) and the all-sky microwave denial and its control experiment (Figure 8(b)). Mean increment differences are not identical to mean analysis differences because they are computed from the difference between first-guess and analysis in each cycle and include the evolution of the model first guess with time due to the difference between an experiment and its control. In any case, the increment difference indicates the areas where most of the work is performed in the analysis on the mean state. 
(a)

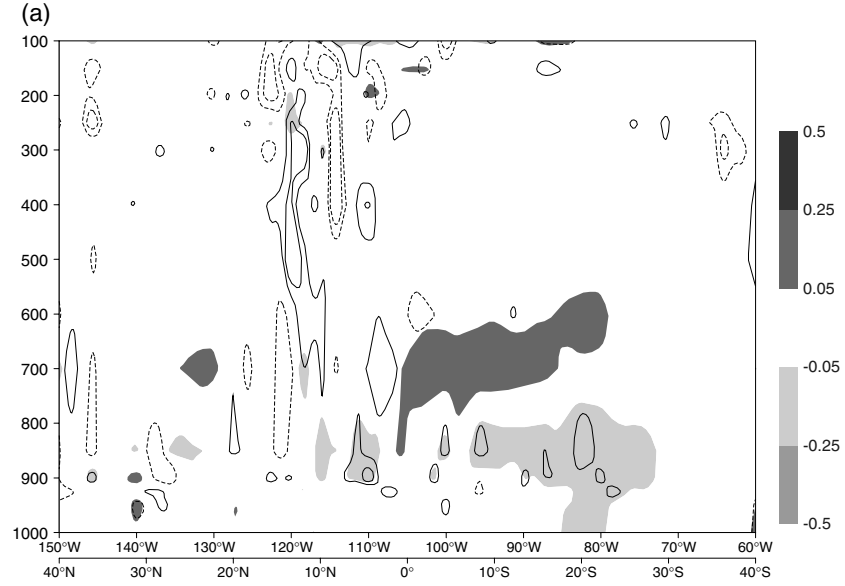

(b)

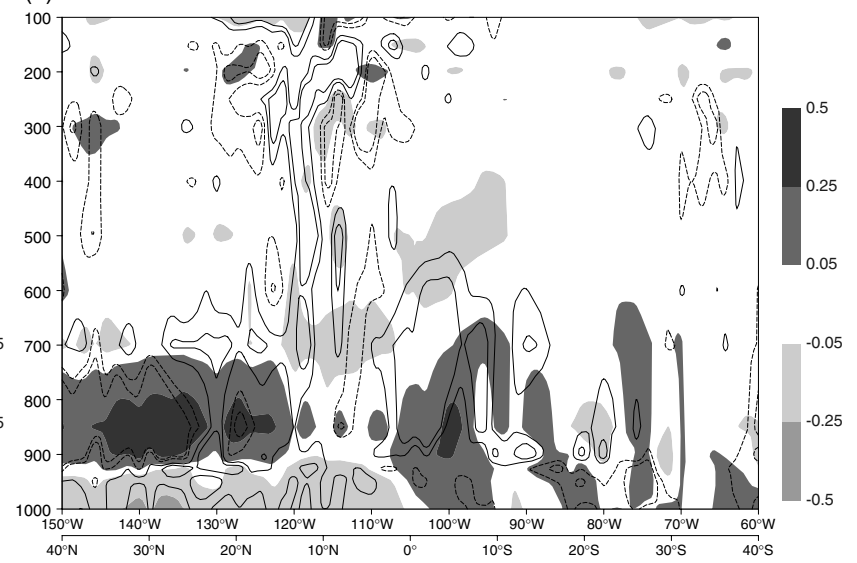

Figure 8. Zonal cross-sections of difference in mean temperature (grey shading, K) and relative humidity increments (contours with positive solid and negative dashed) between (a) clear + cloud-affected and clear-sky only infrared radiance and (b) all-sky and no microwave data assimilation. The cross-section is along the line shown in Figures 6 and 7, i.e. $150-60^{\circ} \mathrm{W}$ and $40^{\circ} \mathrm{S}-40^{\circ} \mathrm{N}$.

Figure 8 (a) highlights again the areas of the $700-850 \mathrm{hPa}$ dipole of positive and negative increments above the temperature inversion in the presence of stratocumulus clouds between $30^{\circ} \mathrm{S}$ and the Equator. The $700 \mathrm{hPa}$ warming is more pronounced further away from the areas of highest cloud occurrence, while the $800 \mathrm{hPa}$ cooling is strongest where the most persistent cloud cover is present. The vertical cross-section of $\mathrm{RH}$ increments does not indicate a significant moisture response, again due to the fact that infrared radiances have a strong direct sensitivity to temperature.

The all-sky microwave observations produce much stronger increments with much deeper structures due to their primary sensitivity to integrated moisture and liquid and the broadening effect by the moisture backgrounderror structure functions. Notably, the $850 \mathrm{hPa}$ cooling that was seen near $85^{\circ} \mathrm{W}, 20^{\circ} \mathrm{S}$ from the infrared radiances is also seen in Figure $8(\mathrm{~b})$, but dominated by the general warming at this level as described above. This pattern is only dissolved by the intensive convection across the ITCZ $\left(115^{\circ} \mathrm{W}, 10^{\circ} \mathrm{N}\right)$ and becomes even stronger north of the ITCZ. North of $15^{\circ} \mathrm{N}$, the data produce low-level cooling and a warmer, drier level at $850 \mathrm{hPa}$ thus increasing stability. In the ITCZ, the entire troposphere above $800 \mathrm{hPa}$ is cooled in both experiments leading to reduced updraught at mid levels. This is consistent between infrared and microwave assimilation experiments.

The general message is that cloud-affected infrared and microwave radiances produce temperature increments that are consistent near $700 \mathrm{hPa}$ above low-level clouds, but show the opposite sign in most areas below, except in the presence of overcast clouds. The mechanisms through which both observation types act on the temperature analysis are rather different because infrared radiances have a strong direct sensitivity to atmospheric temperature and the weighting functions sharpen above overcast clouds. In these situations, moisture and wind are only weakly affected while microwave radiances primarily affect moisture in deep layers. This signal becomes further distributed by the vertical moisture structure functions and produces quite significant response in temperature.

This example demonstrates the individual contribution of cloud- and precipitation-affected infrared and microwave radiances in an operational NWP system that can be assumed rather typical for all data assimilation and modelling systems covered in the article. The impact on temperature and moisture in the analysis is noticeable but not identical between the two observation types due to the significantly different sensitivity to temperature, moisture and cloud variables. Most experiments seem to produce beneficial overall impact despite the fact that none of the centres has optimized its data assimilation systems regarding control variables and background-error statistics. This is quite a remarkable result since the many fundamental issues associated with assimilating such data (Errico et al., 2007) do not necessarily promise this success.

\section{Discussion and future plans}

This article summarizes the current development status of the assimilation of satellite observations affected by cloud and precipitation at global and operational NWP centres. Microwave and infrared radiances represent the most widely used observation types. Most centres directly assimilate radiances in clear skies and therefore attempt to extend this system to include also cloud-affected data because the consistent maintenance of radiance observations, including observation error and bias correction definition, has high priority at operational centres. The Met Office slightly deviates from the fully generalized radiance assimilation in that a separate 1D-Var retrieval step preceeds the usage of observations in 4D-Var. The 1D-Var step introduces an opportunity for quality control and is used with cloudaffected observations to determine cloud variables such as cloud-top pressure, emissivity or liquid water content that are then kept fixed in 4D-Var.

The most fundamental aspect of cloud-affected data usage is the question of whether cloud information is used to produce a cleaner temperature and moisture analysis, or also to constrain cloud variables for a better moist physics analysis in 4D-Var. Mostly for infrared and microwave sounder radiances, a temperature analysis that minimizes aliasing from cloud to temperature sensitivity is targeted while microwave imager radiances, due to their sensitivity to integrated contents of moisture and condensate, are used to constrain cloud variables as well. In both applications though, the reduction of potential aliasing of cloud information into temperature and moisture 
represents the main benefit, whether or not clouds are directly constrained in the analysis.

An aspect of the fundamental problems presented here is that numerical weather simulation models are designed to represent spatially and statistically averaged clouds whereas satellite instruments observe a very different spatial average of real clouds. It thus makes sense to focus on better temperature and moisture analyses because comparing weather model clouds with observed clouds is ambiguous because of their fundamental differences in filtering. Once the representation of clouds in models converges to that of observations, all-sky infrared and microwave radiances can be exploited more aggressively to simultaneously update cloud, precipitation, moisture and temperature state estimates.

Among NWP centres, the current approaches to assimilate infrared radiances are rather similar in that a retrieval of cloud top and (effective) cloud emissivity is performed, usually without an explicit modelling of multiple scattering effects inside clouds. The systems differ by their treatment of fractional cloud amount; the more conservative systems (ECMWF) are limited to fully overcast systems, while other centres (Météo-France, Environment Canada, Met Office) perfom experiments with fractional clouds to enhance data volume and thus impact. The advantage of the limitation to overcast clouds is that clouds can be treated as a single-layer emitter whose radiative properties are defined by its top temperature. Once fractional cloud cover is included, multiple layering and ambiguities between cloudlayer heights and emissivities have to be accounted for, and the strong sensitivity of radiances to changes of these quantities can introduce significant nonlinearities into the minimization.

When bulk impact between the infrared radiance assimilation systems is compared, areas with persistent lowlevel (stratocumulus) cloud cover dominate the picture. Near cloud top $(850 \mathrm{hPa})$, all systems produce negative mean temperature increments, i.e. the additional radiance observations try to reduce temperatures. Since all systems use cloud-top heights retrieved from the observations rather than the model clouds in the analysis, these temperature increments may not coincide with the model cloud top. If model cloud tops and the associated temperature inversions are systematically misplaced in the models, the observations would therefore aim at shifting the inversion. Above clouds $(700 \mathrm{hPa})$, the mean temperature increments change sign thus producing an overall temperature lapse rate change in these situations. Generally, less impact is seen for high clouds and weak coupling between the resulting temperature and wind analysis is observed, even though all centres note an improvement of forecast scores when assimilating cloudaffected infrared radiances.

Microwave imagers represent the most important lowertropospheric moisture observing system, and the radiance impact on temperature, moisture and wind analysis mostly originates from this moisture sensitivity being propagated through the dynamics and balance operators in $4 \mathrm{D}-$ Var. Examples of this impact have been shown for the same areas where infrared radiance impact is strongest, namely subtropical and tropical low-level clouds. Here, microwave radiances produce rather deep increment structures driven by broad weighting and 4D-Var vertical structure functions with much less dependence on vertical cloud location. Moisture and temperature increments are usually opposite to each other where moistening is co-located with cooling and drying with warming.

In the area with the most persistent amounts of cloud cover, the infrared and microwave radiance impact on $850 \mathrm{hPa}$ temperature analysis is remarkably consistent. Away from these regions, the microwave data impact dominates the analysis because more infrared radiances are excluded due to fractional cloud cover. The general impact of microwave imager radiances on the wind analysis is noticeable and both infrared and microwave observations produce a cooling throughout the depth of the ITCZ.

All centres are aiming at a similar strategy in the near future, i.e. the extension of infrared radiance usage to non-overcast cloud situations and the generalization of the microwave imager radiance usage as described above. Open issues are the improvement of moist control variables and, in particular, more situation- and cloud-specific backgrounderror formulations. The latter is a great challenge but is expected to produce major changes, also in clear skies, because of the current, rather static error correlations and the lack of distinction between errors inside and outside clouds. It is expected that the ensemble-based systems can greatly improve the model background error specification, even if $4 \mathrm{D}$-Var remains the main analysis type.

\section{Acknowledgements}

Alan Geer was funded by the EUMETSAT Fellowship programme, and Min-Jeong Kim by the Joint Center for Satellite Data Assimilation. The authors are grateful for the valuable comments and suggestions from two reviewers. The work of Rob Hine on improving the figures is greatly appreciated.

\section{References}

Anderson SR. 2002. 'The impact of observations on mesoscale model forecasts of 3-hourly rainfall accumulations - Updated results'. Forecasting Research Tech. Report 385, Met Office: Exeter, UK. http://www.metoffice.gov.uk

Andersson E, Pailleux J, Thépaut J-N, Eyre JR, McNally AP, Kelly GA, Courtier P. 2004. Use of cloud-cleared radiances in three/fourdimensional variational data assimilation. Q. J. R. Meteorol. Soc. 120: $627-653$.

Andersson E, Hólm E, Bauer P, Beljaars A, Kelly GA, McNally AP, Simmons AJ, Thépaut J-N, Tompkins AM. 2007. Analysis and forecast impact of the main humidity observing system. Q. J. R. Meteorol. Soc. 133: $1473-1485$

Arakawa A, Schubert WH. 1974. Interaction of a cumulus cloud ensemble with the large-scale environment, Part I. J. Atmos. Sci. 31: 674-701.

Auligné T. 2007. 'Assimilation variationnelle des observations de sounders infra rouges hyperspectraux: correction de biais et detection nuageuse'. PhD thesis, Paul Sabatier University: Toulouse, France.

Bauer P, Lopez P, Benedetti A, Salmond D, Moreau E. 2006a. Implementation of $1 \mathrm{D}+4 \mathrm{D}-\mathrm{Var}$ assimilation of precipitation affected microwave radiances at ECMWF. Part I: 1D-Var. Q. J. R. Meteorol. Soc. 132: 2277-2306.

Bauer P, Lopez P, Benedetti A, Salmond D, Saarinen S, Bonazzola M. 2006b. Implementation of $1 \mathrm{D}+4 \mathrm{D}-\mathrm{Var}$ assimilation of precipitation affected microwave radiances at ECMWF. Part II: 4D-Var. Q. J. R. Meteorol. Soc. 132: 2307-2332.

Bauer P, Geer AJ, Lopez P, Salmond D. 2010. Direct 4D-Var assimilation of all-sky radiances. Part I: Implementation. Q. J. R. Meteorol. Soc. 136: $1868-1885$

Bechtold P, Bazile E, Guichard F, Mascart P, Richard E. 2001. A mass flux convection scheme for regional and global models. Q. J. R. Meteorol. Soc. 127: 869-886.

Bechtold P, Köhler M, Jung T, Doblas-Reyes F, Leutbecher M, Rodwell MJ, Vitart F, Balsamo G. 2008. Advances in simulating 
atmospheric variability with the ECMWF model: From synoptic to decadal time-scales. Q. J. R. Meteorol. Soc. 134: 1337-1351.

Belair S, Mailhot J, Girard C, Vaillancourt P. 2005. Boundary layer and shallow cumulus clouds in a medium-range forecast of a large-scale weather system. Mon. Weather Rev. 133: 1938-1960.

Benjamin SG, Devenyi D, Weygandt SS, Brundage KJ, Brown JM, Grell GA, Kim D, Schwartz BE, Smirnova TG, Smith TL, Manikin GS 2004a. An hourly assimilation/forecast cycle: The RUC. Mon. Weather Rev. 132: 495-518.

Benjamin SG, Brown JM, Weygandt SS, Smith TL, Schwartz B, Moninger WR. 2004b. 'Assimilation of surface cloud, visibility, and current weather observations in the RUC'. In Preprints for 16th Conference on Numerical Weather Prediction, Seattle. Amer. Meteorol. Soc: Boston, MA.

Benjamin SG, Weygandt SS, Brown JM, Smirnova TG, Devenyi D, Brundage K, Grell GA, Peckham S, Schlatter T, Smith TL, Manikin G. 2007. 'From the radar enhanced RUC to the WRF-based rapid refresh' In Proceedings of 18th Conference on Numerical Weather Prediction, Park City, Utah, USA. Amer. Meteorol. Soc: Boston, MA.

Benjamin SG, Jamison BD, Moninger WR, Sahm SR, Schwartz B, Schlatter TW. 2010. Relative short-range forecast impact from aircraft, profiler, radiosonde, VAD, GPS-PW, METAR, and Mesonet observations via the RUC hourly assimilation cycle. Mon. Weather Rev. 138: 1319-1343.

Bennartz R, Greenwald T. 2011. Scattering radiative transfer in data assimilation. Q. J. R. Meteorol. Soc. submitted.

Bormann N, Collard A, Bauer P. 2010. Estimates of spatial and inter-channel observation error characteristics for current sounder radiances for NWP. Part II: Application to AIRS and IASI data. Q. J. R. Meteorol. Soc. 136: 1051-1063.

Bougeault P. 1985. A simple parameterization of the large-scale effects of cumulus convection. Mon. Weather Rev. 113: 2108-2121.

Bouteloup Y, Bouyssel F, Marquet P. 2005. 'Improvments of Lopez's prognostic large-scale cloud and precipitation scheme'. ALADIN Newsletter 28: 66-73.

Brousseau P, Bouttier F, Hello G, Seity Y, Fischer C, Berre L, Montmerle T, Auger L, Malardel S. 2008. 'A prototype convectivescale data assimilation system for operation: The AROME-RUC' Tech. Report 68, HIRLAM. Available from: http://hirlam.org/

Cardinali C, Prates F. 2011. Performance measurement with advanced diagnostic tools of all-skymicrowave imager radiances in $4 \mathrm{D}$-Var. $Q$. J. R. Meteorol. Soc. DOI: 10.1002/qj.865.

Caumont O, Ducrocq V, Wattrelot E, Jaubert G, Pradier-Vabre S. 2010 $1 \mathrm{D}+3 \mathrm{D}$-Var assimilation of radar reflectivity data: A proof of concept. Tellus 62A: 173-187.

Chen Y, Weng F, Han Y, Liu Q. 2008. Validation of the Community Radiative Transfer Model (CRTM) by using CloudSat data. J. Geophys. Res. 113: DOI: 10.1029/2007JD009561.

Collard AD, McNally AP. 2009. The assimilation of IASI radiances at ECMWF. Q. J. R. Meteorol. Soc. 135: 1044-1058.

Côté J, Gravel S, Méthot A, Patoine A, Roch M, Staniforth A. 1998. The operational CMC-MRB Global Environmental Multiscale (GEM) model. Part I: Design considerations and formulation. Mon. Weather Rev. 126: 1373-1396.

Davies T, Cullen MJP, Malcolm AJ, Mawson MH, Staniforth A White AA, Wood N. 2005. A new dynamical core for the Met Office;s global and regional modelling of the atmosphere. Q. J. $R$ Meteorol. Soc. 131: 1759-1782.

Derber JC, Wu W-S. 1998. The use of TOVS cloud-cleared radiances in the NCEP SSI analysis system. Mon. Weather Rev. 126: 2287-2299.

Ducrocq V, Ricard D, Lafore J-P, Orain F. 2002. Storm-scale numerical rainfall prediction for five precipitating events over France: On the importance of the initial humidity field. Weather and Forecasting 17: $1236-1256$.

Ebert EE, Janowiak JE, Kidd C. 2007. Comparison of near-real-time precipitation estimates from satellite observations and numerical models. Bull. Amer. Meteorol. Soc. 88: 47-64.

Errico R, Bauer P, Mahfouf J-F. 2007. Assimilation of cloud and precipitation data: Current issues and future prospects. J. Atmos. Sci. 64: 3789-3802.

Errico R, Bauer P, Mahfouf J-F. 2008. Reply to comments on 'Issues regarding the assimilation of cloud and precipitation data'. J. Atmos. Sci. 65: 3348-3350.

Fillion L, Tanguay M, Lapalme E, Denis B, Desgagne M, Lee V, Ek N, Liu Z, Lajoie M, Caron J-F, Pagé C. 2010. The Canadian regional data assimilation and forecasting system. Weather and Forecasting 25 $1645-1669$.
Garand L, Beaulne A, Wagneur N, Hallé J, Heilliette S. 2007. 'Implementation of AIRS assimilation at MSC'. In Proceedings of Joint 2007 EUMETSAT Meteorological Satellite Conference and 15th Satellite Meteorology and Oceanography Conference. Amer. Meteorol. Soc: Boston, MA.

Garand L, Pancrati O, Heilliette S. 2011. Validation of forecast cloud parameters from multispectral AIRS radiances. Atmos.-Ocean 49: 121-137.

Gauthier P, Tanguay M, Laroche S, Pellerin S, Morneau J. 2007. Extension of $3 \mathrm{D}$-Var to $4 \mathrm{D}$-Var: Implementation of $4 \mathrm{D}$-Var at the Meteorological Service of Canada. Mon. Weather Rev. 135: 2339-2354.

Geer AJ, Bauer P. 2010. 'Enhanced use of all-sky microwave observations sensitive to water vapour, cloud and precipitation'. Tech. Memo. 620, ECMWF: Reading, UK.

Geer AJ, Bauer P. 2011. Observation errors in all-sky data assimilation. Q. J. R. Meteorol. Soc. DOI: 10.1002/qj.830.

Geer AJ, Bauer P, Lopez P. 2008. Lessons learnt from the operational $1 \mathrm{D}+4 \mathrm{D}-\mathrm{Var}$ assimilation of rain- and cloud-affected SSM/I observations at ECMWF. Q. J. R. Meteorol. Soc. 134: $1513-1525$.

Geer AJ, Bauer P, Lopez P. 2010. Direct 4D-Var assimilation of all-sky radiances. Part II: Assessment. Q. J. R. Meteorol. Soc. 136: 1886-1905.

Geleyn J-F. 1987. 'Use of a modified Richardson number for parameterizing the effect of shallow convection'. Short- and Mediumrange Numerical Weather Prediction. In Collection of papers presented at the WMO/IUGG NWP Symposium, Tokyo, Japan. WMO: Geneva.

Gregory D, Allen S. 1991. 'The effect of convective downdraughts upon NWP and climate simulations'. In Proceedings of the ninth conference on numerical weather prediction, Denver, Colorado. 122-123.

Gregory D, Rowntree PR. 1990. A mass-flux convection scheme with representation of cloud ensemble characteristics and stabilitydependent closure. Mon. Weather Rev. 118: 1483-1506.

Gregory D, Kershaw R, Inness PM. 1997. Parametrization of momentum transport by convection II: Tests in single-column and general circulation models. Q. J. R. Meteorol. Soc. 123: 1153-1183.

Grell GA. 1993. Prognostic evaluation of assumptions used by cumulus parameterizations. Mon. Weather Rev. 121: 764-787.

Guidard V, Fourrié N, Brousseau P, Rabier F. 2011. Impact of IASI assimilation at global and convective scales and challenges for the assimilation of cloudy scenes. Q. J. R. Meteorol. Soc. DOI: 10.1002/qj.928.

Han J, Pan H-L. 2011. Revision of convection and vertical diffusion schemes in the NCEP global forecast system. Mon. Weather Rev. submitted.

Harrison D, Macpherson B, Naylor M, Renshaw RJ, Scovell R. 2008. 'Impact of assimilating a European radar composite into an NWP model'. In Proceedings of 5th European Conference on Radar in Meteorology and Hydrology, Helsinki, Finland.

Heilliette S, Garand L. 2007. A practical approach for the assimilation of cloudy infrared radiances and its evaluation using AIRS simulated observations. Atmos.-Ocean 22: 211-225.

Hólm E, Andersson E, Beljaar A, Lopez P, Mahfouf J-F, Simmons AJ, Thépaut J-N. 2002. 'Assimilation and modelling of the hydrological cycle: ECMWF's status and plans'. Tech. Memo. 383, ECMWF: Reading, UK.

Honda Y, Nishijima M, Koizumi K, Ohta Y, Tamiya K, Kawabata T, Tsuyuki T. 2005. A pre-operational variational data assimilation system for a non-hydrostatic model at the Japan Meteorological Agency: Formulation and preliminary results. Q. J. R. Meteorol. Soc. 131: $3465-3475$.

Japan Meteorological Agency. 2007. 'Outline of the Operational Numerical Weather Prediction at the Japan Meteorological Agency'. http://www.jma.go.jp/jma/jma-eng/jma-center/nwp/ outline-nwp/index.htm

Jones CD, Macpherson B. 1997. A latent heat nudging scheme for the assimilation of precipitation data into an operational mesoscale model. Meteorol. Appl. 4: 269-277.

Kain J, Fritsch JM. 1990. A one-dimensional entraining/detraining plume model and its application in convective parameterization. J. Atmos. Sci. 47: 2784-2802.

Kain J, Fritsch JM. 1993. Convective parameterization for mesoscale models: The Kain-Fritsch scheme. The representation of cumulus convection in numerical models. J. Atmos. Sci. 47: 2784-2802.

Kleist DT, Parrish DF, Derber JC, Treadon R, Wu W, Lord S. 1998. Introduction of the GSI into the NCEP Global Data Assimilation System. Mon. Weather Rev. 126: 2287-2299. 
Koizumi K, Ishikawa Y, Tsuyuki T. 2005. Assimilation of precipitation data to JMA mesoscale model with a four-dimensional variational method and its impact on precipitation forecasts. Sci. Online Letts. Atmos. 1: 45-48.

Kummerow C, Hong Y, Olson WS, Yang S, Adler RF, McCollum J, Ferraro RR, Petty G, Shin D-B, Wilheit TT. 2001. The evolution of the Goddard profiling algorithm (GPROF) for rainfall estimation from passive microwave sensors. J. Appl. Meteorol. 40: 1801-1820.

Laroche S, Gauthier P, Tanguay M, Pellerin S, Morneau J. 2007. Impact of the different components of 4D-Var on the Global Forecast System of the Meteorological Service of Canada. Mon. Weather Rev. 135: 2355-2364.

Lopez P. 2002. Implementation and validation of a new prognostic largescale cloud and precipitation scheme for climate and data-assimilation purposes. Q. J. R. Meteorol. Soc. 128: 229-257.

Lopez P. 2011. Direct 4D-Var assimilation of NCEP Stage IV radar and gauge precipitation data at ECMWF. Q. J. R. Meteorol. Soc. submitted.

Lopez P, Bauer P. 2007. 1D+4D-Var assimilation of NCEP Stage IV radar and gauge hourly precipitation data at ECMWF. Mon. Weather Rev. 135: 2506-2524.

Lopez P, Moreau E. 2005. A convection scheme for data assimilation: Description and initial tests. Q. J. R. Meteorol. Soc. 131: 409-436.

Lopez P, Benedetti A, Bauer P, Janisková M, Köhler M. 2007. Experimental 2D-Var assimilation of ARM cloud and precipitation observations. Q. J. R. Meteorol. Soc. 132: 1325-1347.

Macpherson B. 2001. Operational experience with assimilation of rainfall data in the Met Office mesoscale model. Meteorol. Atmos. Phys. 76: $3-8$.

Mahfouf J-F. 2005. Linearization of a simple moist convection scheme for large-scale NWP models. Mon. Weather Rev. 133: 1655-1670.

Marécal V, Mahfouf J-F. 2002. Four-dimensional variational assimilation of total column water vapor in rainy areas. Mon. Weather Rev. 130: $43-58$.

McNally AP. 2002. A note on the occurrence of cloud in meteorologically sensitive areas and the implications for advanced infrared sounders. Q. J. R. Meteorol. Soc. 128: 2551-2556.

McNally AP. 2009. The direct assimilation of cloud-affected satellite infrared radiances in the ECMWF 4D-Var. Q. J. R. Meteorol. Soc. 134: 1214-1235.

McNally AP, Watts PD. 2003. A cloud-detection algorithm for highspectral-resolution infrared sounders. Q. J. R. Meteorol. Soc. 129: 2411-2323.

Michel Y, Auligné T, Montmerle T. 2011. Diagnosis of convective scale background-error covariances within and outside of precipitating areas. Mon. Weather Rev. submitted.

Ménétrier B, Montmerle T. 2011. Heterogeneous background-error covariances for the analysis and forecast of fog events. Q. J. R. Meteorol. Soc. DOI: 10.1002/qj.802.

Pan H-L, Wu W-S. 1994. 'Implementing a mass-flux convective parameterization package for the NMC Medium Range Forecast Model'. In Preprints for 10th Conference on Numerical Weather Prediction, Portland, Oregon. Amer. Meteorol. Soc: Boston. 96-98.

Pangaud T, Fourrié N, Guidard V, Dahoui M, Rabier F. 2009. Assimilation of AIRS radiances affected by mid- to low-level clouds. Mon. Weather Rev. 137: 4276-4292.

Pavelin EG, English SJ, Eyre JR. 2008. The assimilation of cloud-affected infrared satellite radiances for numerical weather prediction. Q. J. R. Meteorol. Soc. 134: 737-749.

Phalippou L. 1996. Variational retrieval of humidity profile, wind speed and cloud liquid-water path with the SSM/I: Potential for numerical weather prediction. Q. J. R. Meteorol. Soc. 122: 327-335.

Pincus R, Hofmann RJP, Anderson JL, Raeder K, Collins N, Whitaker JS. 2011. Can fully accounting for clouds in data assimilation improve short-term forecasts by global models? Mon. Weather Rev. 139: 946-957.

Pudykiewicz J, Benoit R, Mailhot J. 1992. Inclusion and verification of a predictive cloud water scheme in a regional weather prediction model. Mon. Weather Rev. 120: 612-626.

Rabier F, Järvinen H, Klinker E, Mahfouf J-F, Simmons A. 2000. The ECMWF operational implementation of four-dimensional variational assimilation. Part I: Experimental results with simplified physics. Q. J. R. Meteorol. Soc. 126: 1143-1170.
Rawlins F, Ballard SP, Bovis KJ, Clayton AM, Li D, Inverarity GW, Lorenc AC, Payne TJ. 2007. The Met Office global four-dimensional variational data assimilation scheme. Q. J. R. Meteorol. Soc. 133: 347-362.

Renshaw R, Francis P. 2011. Variational assimilation of cloud fraction in the operational Met Office Unified Model. Q. J. R. Meteorol. Soc. submitted.

Skamarock WC, Klemp JB, Dudhia J, Gill DO, Barker DM, Wang W, Powers JG. 2005. 'A Description of the Advanced Research WRF Version 2'. Technical Note 468+STR, NCAR: Boulder, USA http://www.mmm.ucar.edu/wrf/users/pub-doc.html

Smith RNB. 1990. A scheme for predicting layer clouds and their water content in a general circulation model. Q. J. R. Meteorol. Soc. 116: $435-460$.

Sommeria G, Deardorff JW. 1977. Subgrid-scale condensation in models of nonprecipitating clouds. J. Atmos. Sci. 34: 344-355.

Stiller O, Ballard SP. 2009a. Efficient moist physics schemes for data assimilation. I: Large-scale clouds and condensation. Q. J. R. Meteorol. Soc. 135: 707-720.

Stiller O, Ballard SP. 2009b. Efficient moist physics schemes for data assimilation. II: Deep convection. Q. J. R. Meteorol. Soc. 135: 721-738.

Sundqvist H. 1978. A parametrization scheme for non-convective condensation including prediction of cloud water content. Q. J. R. Meteorol. Soc. 104: 677-690.

Sundqvist H, Berge E, Kristjansson KE. 1989. Condensation and cloud parameterization studies with a mesoscale numerical weather prediction model. Mon. Weather Rev. 117: 1641-1657.

Tauchi T, Takeuchi Y, Sato Y. 2004. Assimilation of the Aqua/AMSR-E data to numerical weather predictions. Proceedings of Geoscience and Remote Sensing Symposium, IGARSS '04. IEEE International 5: 3199-3202.

Taylor R, Renshaw R, Saunders R, Francis P. 2008. 'Assimilation of SEVIRI cloud-top parameters in the Met Office regional forecast model'. In Proceedings of the 2008 EUMETSAT Meteorological Satellite Conference, Darmstadt, Germany.

Tiedtke M. 1989. A comprehensive mass flux scheme for cumulus parameterization in large-scale models. Mon. Weather Rev. 117: 1779-1800.

Tiedtke M. 1993. Representation of clouds in large-scale models. Mon. Weather Rev. 121: 3040-3061.

Tompkins AM. 2008. 'Cloud parametrization'. In Proceedings of Workshop on parametrization of subgrid-scale processes. ECMWF: Reading, UK.

Tompkins AM, Janisková M. 2004. A cloud scheme for data assimilation: Description and initial tests. Q. J. R. Meteorol. Soc. 130: 2495-2517.

Vukicevic T. 2008. Comments on 'Issues regarding the assimilation of cloud and precipitation data'. J. Atmos. Sci. 65: 3344-3347.

Wattrelot E, Caumont O, Pradier-Vabre S, Jurasek M, Haase G. 2008. ' $1 \mathrm{D}+3 \mathrm{D}-\mathrm{Var}$ assimilation of radar reflectivities in the preoperational AROME model at Météo-France’. In Proceedings of Erad2008, Helsinki, Finland.

Wattrelot E. 2009. Implementation of the 1D+3D-Var assimilation of radar reflectivities in the AROME model at Météo-France. In Proceedings of Joint 19th ALADIN Workshop and HIRLAM ASM 2009, May 2009, Utrecht, Netherlands.

Weygandt SS, Benjamin SG, Smirnova TG, Brown JM. 2008. 'Assimilation of radar reflectivity data using a diabatic digital filter within the Rapid Update Cycle'. In Preprints for 12th Conference on IOAS-AOLS. New Orleans. Amer. Meteorol. Soc: Boston, MA.

Wilson DR, Bushell AC, Kerr-Munslow AM, Price JD, Morcrette CJ. 2008. PC2: A prognostic cloud fraction and condensation scheme. I: Scheme description. Q. J. R. Meteorol. Soc. 134: 2093-2107.

Wu W-S, Purser RJ, Parrish DF. 2002. Three-dimensional variational analysis with spatially inhomogeneous covariances. Mon. Weather Rev. 130: 2905-2916.

Zadra A, Buehner M, Laroche S, Mahfouf J-F. 2004. Impact of the GEM model simplified physics on the extratropical singular vectors. Q. J. R. Meteorol. Soc. 130: 2541-2013.

Zhao Q, Carr F. 1997. A prognostic cloud scheme for operational NWP models. Mon. Weather Rev. 125: 1931-1953. 